University of Denver

Digital Commons @ DU

$1-1-2019$

\title{
Beyond School Engagement: School Adaptation and Its Role in Bolstering Resilience Among Youth Who Have Been Involved with Child Welfare Services
}

Skyler S. Leonard

University of Denver

Follow this and additional works at: https://digitalcommons.du.edu/etd

Part of the Child Psychology Commons

\section{Recommended Citation}

Leonard, Skyler S., "Beyond School Engagement: School Adaptation and Its Role in Bolstering Resilience Among Youth Who Have Been Involved with Child Welfare Services" (2019). Electronic Theses and Dissertations. 1672.

https://digitalcommons.du.edu/etd/1672

This Dissertation is brought to you for free and open access by the Graduate Studies at Digital Commons @ DU. It has been accepted for inclusion in Electronic Theses and Dissertations by an authorized administrator of Digital Commons@DU. For more information, please contact jennifer.cox@du.edu,dig-commons@du.edu. 
Beyond School Engagement: School Adaptation and Its Role in Bolstering Resilience Among Youth Who Have Been Involved with Child Welfare Services

\author{
A Dissertation \\ Presented to \\ the Faculty of Social Sciences \\ University of Denver \\ In Partial Fulfillment \\ of the Requirements for the Degree \\ Doctor of Philosophy \\ by \\ Skyler S. Leonard \\ August 2019 \\ Advisor: Omar G. Gudiño, Ph.D.
}


Author: Skyler S. Leonard

Title: Beyond School Engagement: School Adaptation and Its Role in Bolstering Resilience Among Youth Who Have Been Involved with Child Welfare Services Advisor: Omar G. Gudiño, Ph.D.

Degree Date: August 2019

\begin{abstract}
Objective: Youth involved with the child welfare system are at significant risk of poor school functioning and mental health. Little research has explored how the connection to school impacts known relationships between adversity and youth outcomes. The following project sought to shed light on the role of schools in conferring risk or resilience for youth in contact with the child welfare system, with regard to their mental health. The overall aims of this project were to (1) improve our conceptualization of school adaptation, with particular attention to individual variation along multiple dimensions of school adaptation, (2) examine the relationship of school adaptation to important child welfare indicators, and (3) explore the impact of school adaptation on youth mental health.
\end{abstract}

Method: Participants included 2,668 youth (age 4 to 16 at baseline) participating in a national longitudinal study of youth in contact with the child welfare system following an investigation for alleged maltreatment. Youth, teachers, caregivers, and caseworkers provided relevant information at baseline, 18 months, and 36 months. Patterns among a variety of school adaptation indicators were determined via latent profile analysis, relationships between latent profiles and child welfare risk factors were determined using multinomial logistic regression, and relationships between latent profiles and later mental health were explored using hierarchal regression. 
Results: Latent profile analysis supported the interpretation of four profiles of school adaptation in this sample, including a high overall adaptation group, a moderate overall adaptation with somewhat poor behavior group, a low overall adaptation with poor behavior group, and a low overall adaptation with good behavior and low emotional/cognitive engagement group. Aim 2 revealed that school adaptation profiles were related to some demographic variables, but were largely independent of child welfare indicators. Child age and gender predicted profile membership such that girls demonstrated better school adaptation overall than boys, and younger youth demonstrated better school adaptation overall than older youth. Race, alleged type of maltreatment investigated, and substantiation of maltreatment did not significantly predict profile membership. Caseworker reported severity of maltreatment predicted profile membership overall, but differences between groups were not significant. Aim 3 revealed that maltreatment severity and profile membership predicted youth mental health functioning three years later, such that youth in the lowest adaptation group (low overall adaptation with poor behavior) demonstrated the highest symptomology, youth in the high overall adaptation group demonstrated the lowest symptomology, and youth in both the moderate overall adaptation with somewhat poor behavior group and the low overall adaptation with good behavior and low emotional/cognitive engagement group, did not significantly differ from each other and demonstrated mental health problems between the highest and lowest adaptation groups.

Conclusions: The results of the current study demonstrate that school adaptation is a nuanced construct which is not well-represented by a single indicator, or average 
score of multiple indicators, of the ways in which youth interface with school.

Nonetheless, school adaptation is an important factor to consider in order to understand the future mental health of youth in the high-risk group of children and adolescents involved with child welfare services. Implications of the findings and limitations of the current study are discussed. 


\section{TABLE OF CONTENTS}

Chapter One: Introduction

Prevalence of Childhood Maltreatment

Impact of Maltreatment on Mental Health $\ldots \ldots$

Impact of Maltreatment on Academics $\ldots$

Resilience and the Importance of School $\ldots$

The Components of School Adaptation Among the General Population of Youth

Limitations of the School Engagement/Adaptation Literature _............................ 10

School Adaptation Among Maltreated Youth $\ldots \ldots \ldots \ldots$

Aims

Chapter Two: Method

The National Survey of Child and Adolescent Well-Being (NSCAW) _.............. 25

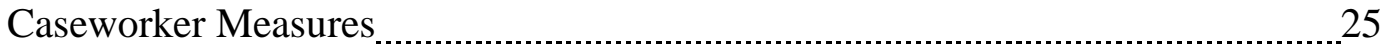

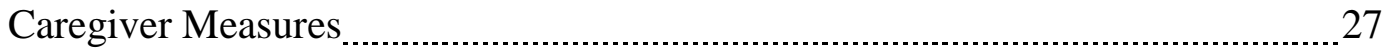

Teacher Measures

Youth Measures

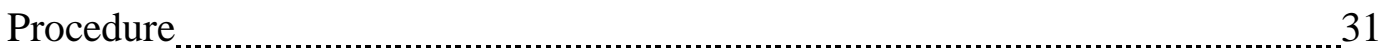

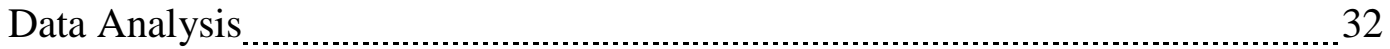

Chapter Three: Results $\ldots \ldots \ldots \ldots$

Descriptive Statistics and Preliminary Analyses _..................................... 35

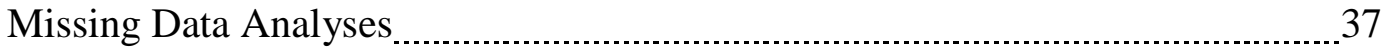

Aim $1 \ldots \ldots \ldots$

Aim $2 \ldots \ldots$

Aim 3

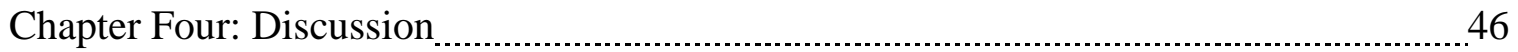

Aim $1 \quad 47$

Aim 2

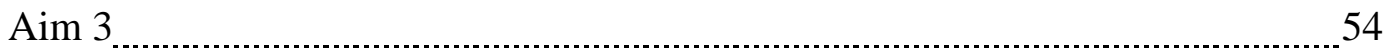

Strengths, Limitations, and Future Directions $\ldots \ldots \ldots$

Conclusion 63

References

Appendices

Appendix A: Tables

Appendix B: Figures 


\section{LIST OF TABLES}

Table 1. Descriptive Statistics for All Variables 80

Table 2. Constructs, Respondents, and Measures for All Variables 82

Table 3. Bivariate Correlations of School Adaptation Indicators 85

Table 4. Fit Indices and Entropies for Latent Profile Analysis Models 86

Table 5. Within Profile Z-Score Means and Significant Differences Between Profiles by Variable 87

Table 6. Within Profile Means and Percentages for Demographic, Child Welfare, and Mental Health Variables. 88

Table 7. Likelihood Ratio Tests of Multinomial Logistic Regression 89

Table 8. Parameter Estimates of the Multinomial Logistic Regression 90

Table 9. Analyses of Variance of Mental Health Symptomology at Wave 4 by Profile 92

Table 10. Hierarchal Regressions Predicting Mental Health Outcomes 93 


\section{CHAPTER ONE: INTRODUCTION}

\section{Prevalence of Childhood Maltreatment}

Childhood abuse and neglect are associated with increased risk for a host of negative outcomes, including mental health problems, obesity, risky sexual behavior, substance abuse, criminal behavior, and even mortality (Gilbert et al., 2009). Youth experiences of maltreatment are a prevalent problem in the United States. The U.S. Department of Health and Human Services estimates that there were 686,000 child victims of abuse and neglect in the United States in the year 2012 (USDHHS, 2013). Of these, $78.3 \%$ were victims of neglect, $18.3 \%$ were physically abused, and $9.3 \%$ were sexually abused. Eighty-two percent of victims were maltreated by one or both of their caregivers (USDHHS, 2013).

For children involved with child welfare services, multiple incidents and forms of maltreatment are a common experience. In a study of 2,251 youth who had been placed in foster care, it was found that $70.4 \%$ of youth had experienced two or more types of caregiver interpersonal trauma, with over $50 \%$ of youth experiencing three or more forms (Greeson et al., 2011). For children and adolescents raised in environments which place them at high risk for repeated, prolonged, and parent-perpetrated maltreatment, it is important to recognize the unique and devastating impacts of cumulative adversity on development. 


\section{Impact of Maltreatment on Mental Health}

The negative impact of maltreatment on youth outcomes has been the subject of much research, demonstrating that the deleterious effects on youth mental health are substantial and predictive of a range of problems (Maguire et al., 2015). In a study comparing emotion regulation patterns among children with maltreatment histories versus non-maltreated controls, $80 \%$ of maltreated children exhibited patterns of emotional dysregulation compared to only $37.2 \%$ of non-maltreated controls (Maughan \& Cicchetti, 2002). Children involved with child welfare services are at risk for internalizing and externalizing problems (Kessler et al., 2010; Moylan et al., 2010). In fact, close to half (47.9\%) of youth in the National Survey of Child and Adolescent WellBeing (NSCAW) experienced clinically significant symptoms of behavioral and emotional problems (Burns et al., 2004). Research has demonstrated that the impact of maltreatment is associated with impaired attachment, deficits in affect and behavioral regulation, dissociation, and impairments in cognition and self-concept (Cook et al., 2005). The negative effects of childhood maltreatment are not isolated to childhood and have demonstrated the potential to negatively impact mental health functioning well into adulthood. Youth who experience maltreatment are at increased risk of future exposure to trauma and lifelong mental health difficulties (Cook et at., 2005; Lereya, Copeland, Costello, \& Wolke, 2015).

\section{Impact of Maltreatment on Academics}

The negative impact of childhood maltreatment has been demonstrated in another important domain of youth adaptation: academics (Maguire et al., 2015). Children who 
have experienced maltreatment do worse than their non-maltreated peers on a variety of school outcomes including grades (Leiter \& Johnsen, 1994), absenteeism rates (Hagborg, Berglund, \& Fahlke, 2018), test scores, grade retention, and special education status (Ryan, Jacob, Gross, Perron, Moore, \& Ferguson, 2018). Children who have experienced maltreatment have also been shown to have more school suspensions (Bell, Bayliss, Glauert, \& Ohan, 2018) and more disciplinary referrals (Kendall-Tackett \& Eckenrode, 1996). Systematic review of the literature highlights that children with maltreatment histories experience significant impairments in academic outcomes across a range of indicators, including special education status, grade retention, lower cognitive development, and lower grades (Romano, Babchishin, \& Marquis, 2014; Veltman \& Browne, 2001). Clearly, maltreatment has the potential to negatively impact multiple levels of adaptation within the school context, but the full impact, mechanisms, and pathways of the relationship between maltreatment and impaired school adaptation are not fully understood.

\section{Resilience and the Importance of School}

Resilience refers to positive adaptation in the context of significant adversity (Luthar, 2015). In over 40 years of studying resilience, several factors have repeatedly emerged as protective for youth exposed to adversity, including relationships with supportive adults and effective schools (Luthar, Cicchetti, \& Becker, 2000). Interestingly, even among youth who have experienced potentially traumatic events, having a stable connection to a supportive adult appears to confer protective effects. In a study of 6- and 7-year-old children living in an urban environment and at high risk for community 
violence exposure, feelings of safety and positive caregiving were related to better performance on cognitive measures (Ratner, Chiodo, Covington, Sokol, \& DelaneyBlack, 2006). A wealth of literature has demonstrated that parenting practices and supportive relationships with parents, are associated with increased resilience among youth (Masten, 2014; Murray Nettles, Mucherah, \& Jones, 2000). What about youth who do not have the benefit of a supportive caregiver relationship and have experienced maltreatment perpetrated by a caregiver? For youth who do not have the benefit of a safe, supportive, and secure attachment at home, perhaps those protective effects can be conferred from another environment.

Research over the past decades has attempted to shed light on what factors bolster resilience among at-risk youth, and one consistent, yet still enigmatic theme is the role of schools in conferring resilience. School factors are often conceptualized as an outcome in the research on youth risk and resilience. School dropout rates, academic achievement, and classroom behavior are used as measures differentiating youth who are succumbing to the effects of adversity versus those who are demonstrating resilience. Less research has explored the role of school factors in the lives of youth who face ongoing adversity outside of school or the role of schools in conferring resilience with regard to other important indicators of youth adjustment, such as mental health symptoms.

The classroom and the school may be the optimal environments in which to support resilience among high-risk youth (Morrison \& Allen, 2007). In a review of studies examining resilient youth who have developed into competent adults, despite a host of risk factors, Benard (1995) argues that protective factors can be grouped into 
three major categories: caring and supportive relationships, positive and high expectations, and opportunities for meaningful participation. Schools have the potential to provide all three. A supportive relationship may take the form of a teacher or another school staff member who expresses interest in a child's life. The classroom is an ideal setting for communicating high expectations for behavior and academics and providing scaffolded supports to meet those expectations. Classrooms and schools can provide opportunities for youth to develop other skills which bolster resilience, such as problemsolving and social skills.

Gilligan (2000) argued that for youth whose home life does not provide a secure base of attachment, other avenues for achieving a secure base, such as the educational or recreational context, may be a viable alternative. He argues that consistent classroom environments and warm relationships with teachers may confer more benefit than therapeutic intervention, including a sense of stability and security. Gilligan (2000) went on to argue that a sense of belonging in school can promote positive adaptation of vulnerable youth across domains including academic performance, motivation, emotional well-being, risk-taking behavior, and response to trauma.

\section{The Components of School Adaptation and School Adaptation Among the General}

\section{Population of Youth}

A wide range of markers of school adaptation and their impact on academic achievement have been investigated, but limited research exists concerning which individual indicators are most important in the lives of youth involved with child welfare services and how those factors impact outcomes other than academic achievement. The 
role of various aspects of the school experience, ranging from behavioral competence (Kremer, Flower, Huang, \& Vaughn, 2016), attendance (Morrissey, Hutchison, \& Winsler, 2014), academic achievement (Diseth, Danielsen, \& Samdal, 2012), relationships with teachers (Murray Nettles, Mucherah, \& Jones, 2000; Roorda, Jak, Zee, Oort, \& Koomen, 2017) and peers (Bond et al., 2007) and self-rated school engagement (Upadyaya \& Salmela-Aro, 2013), have been shown to be important for children in the general population.

Classroom behavior, while commonly thought of as a broad indicator of how youth are doing in school, is also an important predictor of other school-related outcomes. The relationship between classroom behavior and school outcomes begins early, with research demonstrating that preschool behavior problems predict lower literacy in Kindergarten and $1^{\text {st }}$ grade (Bulotsky-Shearer, \& Fantuzzo, 2011) and that early classroom behavioral problems predict trajectories of future behavioral problems (Silver, Measelle, Armstrong, \& Essex, 2005). In a three-year longitudinal study of 790 first graders, consisting of a diverse sample selected from 20 public elementary schools in Baltimore, Alexander, Entwisle, and Dauber (1993) found that teacher ratings of student interest/participation, and attention span/restlessness in first grade strongly predicted grades and performance on standardized tests in subsequent years. Additionally, prosocial and antisocial classroom behavior has been found to significantly predict grades, even when controlling for academically oriented behavior, IQ, attendance, and demographic variables (Wentzel, 1993). Less research has explored the role of classroom behavioral 
problems in predicting other important indicators outside of academic achievement, such as mental health problems or life satisfaction.

School attendance has consistently been implicated in the academic achievement of youth (Morrissey, Hutchinson, \& Winsler, 2014). In a study of 3,171 Ohio schools, examining average attendance rates and academic achievement, Roby (2004) found that school attendance was significantly related to student achievement in all grades examined, including fourth, sixth, ninth, and twelfth grade. In a study of 95 elementary schools in New York City, attendance was found to be a full mediator in the relationship between school facility quality and grades in English language arts and a partial mediator in the relationship between school facility quality and grades in math (Durán-Narucki, 2008). School attendance has also been implicated as an indicator of emerging or existing mental health problems among children and adolescents (DeSocio, \& Hootman, 2004). Again, the research on the role of this indicator of school adaptation and non-school related outcomes is limited.

It should be of no surprise that so much research on school indicators has been dedicated to understanding their impact on academic achievement, as academic achievement has been identified as a critical variable in the lives of youth. Lower academic achievement has been associated with negative outcomes, including antisocial behavior (Patterson, DeBaryshe, \& Ramsey, 2017) and increased rates of emotional/behavioral disorders (Nelson, Benner, Lane, \& Smith, 2004). Higher academic achievement has been associated with positive outcomes, such as increased income 
(Sirin, 2005), higher life satisfaction (Diseth, Danielsen, \& Samdal, 2012), and even longer lives and lower rates of disability (Laditka \& Laditka, 2016).

Teachers and the relationships between youth and teachers also play a critical role in youth school adaptation. Attachment theory states that infants need to form a close bond with at least one primary caregiver in order to achieve healthy social and emotional development (Bowlby, 1969). Bowlby asserted that disruptions in the attachment with a primary caregiver put children at great risk for psychopathology (Cassidy \& Shaver, 1999). Research has shown that other individuals besides parents, such as day care workers, can serve as attachment figures (Howes, Rodning, Galluzzo, \& Myers, 1988). For youth who do not have the benefit of a secure attachment with a stable caregiver, or experience maltreatment perpetrated by their caregiver, perhaps relationships with teachers can serve as a substitute attachment, or the school environment can act as a secure base in which youth can feel safe, supported, have the opportunity to explore their social worlds, and have their needs met for optimal development.

Given the known importance of attachment, it is not surprising that the relationship between students and teachers is a critical aspect of school adaptation. Qualitative research has pointed to teacher-student relationships as an important factor that promotes resilience among youth (Dryden, Johnson Howard, \& McGuire, 1998). Relationships with teachers have been shown to have a positive association with academic performance (Košir \& Tement, 2014; Murray Nettles, Mucherah, \& Jones, 2000), and kindergarten teacher ratings of student-teacher relationship quality has been shown to predict academic and behavioral outcomes through $8^{\text {th }}$ grade, even when 
controlling for cognitive ability and previous behavior (Hamre \& Pianta, 2001). In a meta-analysis including 61 studies and 88,417 students, medium to large effect sizes were found between student-teacher relationships and school engagement, as well as small to medium effect sizes between student-teacher relationships and academic achievement (Roorda, Koomen, Split, \& Oort, 2011). Even among youth with significant internalizing or externalizing problems, higher quality relationships with teachers is predictive of better school outcomes (Baker, Grant, \& Morlock, 2008).

Peer relations are another important aspect of school adaptation. In a longitudinal study of 2,678 eighth grade students, Bond and colleagues (2007) examined associations between social relationships and youth outcomes 2 to 4 years later. They found that social connectedness with peers was associated with better outcomes with regard to mental health, substance use, and educational achievement. Youth with less overall social support, including parents, classmates, teachers, and school support, demonstrate poorer outcomes with regard to clinical and school adjustment (Demaray, \& Malecki, 2002).

One last important domain of school adaptation is school engagement. Not surprisingly, student and teacher reports of youth school engagement are associated with better academic achievement across ages (Chase, Hillard, Geldhof, Warren, \& Lerner, 2014; Fredricks, Blumenfeld, \& Paris, 2004), and low school engagement is an important predictor of dropping out of school (Archambault, Janosz, Fallu, \& Pagani, 2009). Longitudinal studies have shown associations between school engagement and substance use, mental health, school dropout, behavior problems and educational achievement (Bond et al., 2007; Wang \& Fredricks, 2014). 
Finn (1993) conducted what may be the single largest and most comprehensive study of school engagement. In a study of 15,737 eighth graders in public schools, Finn (1993) investigated the association of school participation and academic achievement, after controlling for gender, ethnicity, and socioeconomic status. In this study, the researcher used data covering multiple domains of school engagement, including classroom and school participation, identification with school, participation outside the regular school program, parent involvement in student's school work, and parent involvement with school. Measures included reports from teachers, parents, and students. The study revealed that academic participation and achievement are positively related, but the author highlighted the need for additional research to understand the school engagement of at-risk youth. While the research on the protective role of school engagement is promising, the field is plagued by several substantial limitations regarding the conceptualization of school engagement.

\section{Limitations of the School Engagement/Adaptation Literature}

The current state of the research on school adaptation has several ongoing debates and leaves many unanswered questions. First, given the many aspects of school adaptation and the multiple ways in which school adaptation can be conceptualized (as a predictor, index of functioning, outcome, et cetera), much remains to be determined regarding what dimensions comprise school adaptation and how to measure them. Most importantly, previous conceptualizations of school adaptation are not comprehensive and ignore potentially meaningful indicators of school adaptation. Second, there are limited studies on what school adaptation looks like for at-risk youth and how it relates to 
important risk factors. Third, even more limited is the research on how school adaptation is related to youth mental health.

The literature conceptualizes student engagement as a multifaceted construct that is an important factor for predicting youth outcomes and adjustment. Fredricks, Blumenfeld, and Paris (2004) reviewed the literature on school engagement, including definitions, measures, precursors, and outcomes of engagement. They highlight the need for a richer understanding of this concept. School engagement is usually described as including three dimensions: behavioral engagement, emotional or affective engagement, and cognitive engagement (Fredricks, Blumenfeld, \& Paris, 2004; Jimerson, Campos, \& Greif, 2003). Behavioral engagement typically covers aspects of school engagement such as following or breaking of rules, demonstrating persistence or effort, asking questions, participation in class discussions, or involvement in activities like after school sports or student government. Emotional engagement typically includes attitudes and affective responses towards school, such as feeling bored, happy, sad, or anxious in the classroom, feelings towards educators and peers, and identifying with the school. The final component of school engagement, cognitive engagement, includes motivation and investment in learning as demonstrated by self-regulation, being strategic, and preferences for challenging work.

In a review of 45 studies examining constructs related to school adaptation and its varied definitions, Jimerson, Campos, and Greif (2003) found the same three dimensions of school engagement as mentioned above, as well as five main contexts of school engagement, including academic performance, classroom behavior, extracurricular 
involvement, interpersonal relationships, and school community. They call for a shared definition of school engagement and highlight the notable lack of research exploring socio-cultural variables as they relate to school engagement. They emphasize the need for future investigations to deepen the understanding of school engagement, its role among diverse groups, and how family variables interact with school engagement.

Libbey (2004) echoes that there is disagreement among the field on what to call school engagement and that health and education researchers sometimes use the terms school engagement, school attachment, school bonding, school climate, school involvement, teacher support, and school connectedness to refer to constructs that overlap in their definition and theoretical framework, and that all have something to do with the student's relationships to the school. Libbey (2004) outlined nine common themes that emerge from these varied labels and definitions. These themes include academic engagement, belonging, discipline and fairness, liking school, student voice, extracurricular activities, peer relations, safety, and teacher support. Interestingly, of the over 20 measures reviewed by Libbey (2004), the maximum number of themes captured by any single measure was six, and the majority of measures captured three or fewer themes.

Another important limitation of the school engagement literature concerns the measurement of the construct. The tools that currently exist rely heavily on student reports and perceptions. Student report, while an important component of school adaptation, is one of many possible indicators that may demonstrate overall school adaptation. Of the measures reviewed by Libbey (2004), only one included teacher 
perceptions. Lastly, Libbey's review shows that of the over 20 studies reviewed, only one measure of student engagement had over 20 items, with most measures only utilizing 215 items.

Finally, in their review of the literature, Appleton, Christenson, and Furlong (2008) echo the findings and concerns noted by previous reviews. While these authors also find that the three dimensional conceptualization of school engagement is most common, they also site examples form the literature of two dimension models (behavioral and emotional/affective dimensions) and even four dimension models (behavioral, emotional/affective, cognitive, and psychological dimensions). These scholars note that the research on school engagement has been hindered by the lack of consensus regarding what the construct is and the lack of psychometrically sound measures of the dimensions of the construct.

We argue that the historical difficulty of defining and measuring the construct of school adaptation reflects the fact that school adaptation is a multidimensional construct, consisting of interrelated dimensions that may also make unique contributions to adaptation. School engagement, as it is described by previous investigators, does not capture the totality of school adaptation. The extant literature does not include all of the potentially meaningful dimensions of school adaptation, and additional aspects of school adaptation may need to be considered. The existing literature has explored the dimensionality of school engagement, but additional work is needed to discern how all the indicators of school adaptation fit together and tease apart which dimensions of school adaptation are important for specific outcomes. A second area which warrants 
further investigation is what school adaptation looks like among the population of children who are most at risk, including youth investigated by child welfare services for alleged maltreatment. It is foreseeable that school adaptation may differ considerably by important child-level predictors such as race, gender, age, history of placement in out-ofhome care, type of maltreatment experienced by the youth, and severity of maltreatment.

Perhaps the single largest gap in the research regarding school adaptation is its relationship to mental health. In a longitudinal study of 2,022 twelve to fourteen year-old students, examining school connectedness and mental health, Shochet, Dadds, Ham, and Montague (2010) found that not only were school connectedness and mental health symptoms correlated at both time points, but that school connectedness predicted depressive symptoms at time two. The reverse was not true, indicating that the direction of the relationship between school connectedness and mental health may be unidirectional. Using a diverse sample of 1,025 adolescents and the three-dimensional conceptualization of student engagement, Wang and Peck (2013) identified five profiles of student engagement, including highly engaged, moderately engaged, minimally engaged, emotionally disengaged, and cognitively disengaged. These various profiles differed in their educational and mental health functioning, demonstrating the potential impact of school engagement on mental health or vice versa. Specifically, emotionally disengaged and minimally engaged teens reported higher rates of depression than those who were moderately engaged or cognitively disengaged, while the highly engaged group reported the lowest rates of depression. More research about the relationship between school adaptation and mental health is needed. 


\section{School Adaptation Among Maltreated Youth}

While research on school adaptation usually examines children in the general population, some research has specifically looked at indicators of school adaptation among the unique sample of youth who have experienced maltreatment. Overall, the extant literature has revealed that school adaptation of children and adolescents in this high-risk group is largely reduced when compared to their peers who have not experienced maltreatment (Kaplan, Pelcovitz, \& Labruna, 1999). Research has also consistently shown that the impact of maltreatment is not simply an impact of living in poverty and that the negative impact of maltreatment on school adaptation is over and above that of the impact of living in poverty on school adaptation (Barnett, Vondra, \& Shonk, 1996).

The negative relationship between experiences of maltreatment and academic competence, including grades, test performance, and need for special education services, are clear in the research. Children involved with social services due to abuse and neglect demonstrate lower grades, test scores, and attendance when compared to children from the general school population (Leiter \& Johnsen, 1994; Ryan et al., 2018). Even when comparing school outcomes of maltreated children to those living in low income homes, maltreated children experience lower teacher rated school adaptation, increased use of special education services, and perceive themselves as less competent by late elementary

school (Vondra, Barnett, \& Cicchetti, 1989). Experiences of abuse and neglect have been associated with poor academic test performance (Eckenrode et al., 1993; Ryan at al., 2018) and severe academic delays when compared to their non-abused peers, even when 
controlling for socio-economic status (Jonson-Reid, Drake, Kim, Porterfield, \& Han, 2004; Wodarski, Kurtz, Gaudin, \& Hoowing, 1990).

Characteristics of the maltreatment experienced have also demonstrated importance with regard to school adaptation. In a study examining the impact of maltreatment severity on academic outcomes between adolescent siblings (to control for effects of family background and neighborhood), Slade and Wissow (2007) found that maltreatment intensity was significantly associated with lower grade point average and increased problems completing homework assignments. The type of maltreatment experienced has also been found to have an important impact on educational outcomes. In a large study of 11,835 second grade students, Fantuzzo \& Perlman (2011) controlled for demographics and other risk variables and found that children who had experienced neglect experienced worse academic outcomes than those who had experienced physical abuse. Other researchers have corroborated the findings that abuse and neglect are both detrimental to academic outcomes, but the impact of neglect is over and above that of abuse (Romano, Babchishin, Marguis, \& Fréchette, 2015).

Youth who have experienced maltreatment also demonstrate impairment in school engagement. Youth who have experienced adverse childhood experiences (including physical abuse, emotional abuse, neglect, deprivation, or exposure to violence) display lower rates of school engagement compared to those who have not, but resilience in the face of childhood adversity is associated with increased school engagement (Bethelle, Newacheck, Hawes, and Halfon, 2014). With regard to dimensions of school engagement, Pears, Kim, Fisher, and Yoerger (2013) found that children who had 
experienced maltreatment and were living in foster care had lower cognitive and affective school engagement than non-maltreated, low-income comparison groups, that affective and cognitive engagement mediated the association between maltreatment and academic competence, and that cognitive engagement mediated the relationship between maltreatment and engaging in risk behaviors. Additionally, teacher ratings of student academic engagement demonstrate deficits among maltreated compared to nonmaltreated socioeconomically disadvantaged children from 5-12 years of age (Shonk \& Cicchetti, 2001). Research has demonstrated the importance of school engagement among this high-risk sample in that even among maltreated children, greater school engagement is related to higher levels of well-being and reduced likelihood of delinquency (Tyler, Johnson, \& Brownridge, 2008).

Using data from NSCAW, Leonard, Stiles and Gudiño (2016) examined the main effects of self-reported school engagement on youth outcomes in a sample of children and adolescents involved with the child welfare system. Regression analyses in this sample of 1,766 youth demonstrated that school engagement, averaged across a threeyear period, significantly and positively predicted later academic achievement in both reading and math, as well as negatively predicting internalizing and externalizing symptoms, even when controlling for initial levels of academic achievement or mental health symptoms, race, gender, maltreatment type that led to the investigation, number of out of home placements, and cognitive functioning. While this study was an important step to understanding the relationship between school factors and mental health for youth involved with the child welfare system, it was limited by the use of a single indicator of 
school adaptation, which consisted of an 11-item self-report measure of school engagement. Contradictory to Shochet, Dadds, Ham, and Montague (2010) as described above, research among children involved with the child welfare system has demonstrated a unidirectional relationship between school engagement and mental health in the opposite direction, such that mental health predicts later school engagement, but school engagement does not predict later mental health (Stiles \& Gudiño, 2018).

Conversely, Leonard and Gudiño (2016) did not find significant main effects of school engagement on mental health or academic outcomes in a sub-sample of the previous study including 420 youth who had been placed in out-of-home care following an investigation by child welfare services. Nonetheless, school engagement was significantly correlated with indices of mental health and academic achievement at all time points. Additionally, they found significant main effects of school placement stability on future levels of internalizing and externalizing symptoms. Despite significant bivariate relationships, multivariate analyses suggest that these relationships may be better accounted for by other relevant covariates or may be weaker in the context of youth facing many more challenges, such as removal from home and likely greater severity of maltreatment. Furthermore, these findings may shed light on the limitations of school engagement as a protective factor past a threshold of risk. For example, it is possible that the effects of school engagement are attenuated at higher levels of risk, given that all children in this sample experienced maltreatment severe enough to warrant out-of-home placement. Given these possibilities, the authors conclude that school engagement is only one of many important variables for youth in high-risk contexts. 
Given these discrepancies, additional research is needed to understand the importance of school engagement in a broader context of school adaptation and its impact on youth outcomes.

Classroom behavior is another important indicator of school adaptation in which maltreated youth demonstrate impairment (Kerr, Black, \& Kirshnakumar, 2000). Maltreated youth are significantly more likely than their non-maltreated peers to have disciplinary problems and school suspensions (Maguire et al., 2015). Teachers report that maltreatment results in increased difficulties with inattention and disruptive behaviors in the classroom (Gamanche Martin, Cromer, \& Freyd, 2010). In a review of the literature, increased teacher report of classroom behavioral problems is common for children that have experienced maltreatment (Romano, Babchishin, Marguis, \& Fréchette, 2015).

Children and adolescents who have experienced maltreatment also exhibit impairment across a host of other indicators related to school adaptation compared to non-maltreated peers. Studies have repeatedly found that maltreated youth have poorer attendance rates than the general school population (Hagborg, Berglund, \& Fahlke, 2018; Kiesel, Piescher, \& Edleson, 2016), with some research finding that the negative impact of maltreatment is worse for absenteeism than for grades (Leiter, 2007), possibly in an attempt to conceal maltreatment (Kearney, 2008). Maltreated youth are also less likely than non-maltreated peers to have strong relationships with their teachers (Lynch \& Cicchetti, 1992) and with their peers (Benedini, Fagan, \& Gibson, 2016; Staudt, 2001). Clearly, maltreated youth are at risk for failure in the school context across a variety of dimensions, but this is an area which requires further investigation. 
The extant research leaves several areas of school adaptation that need further exploration. First, we are not aware of any studies that have explored potential profiles and dimensions of school adaptation utilizing student report, teacher report, caregiver report, school records, as well as reports from other professionals, such as caseworkers, or profiles that encapsulate more than the theorized three-dimensions of school adaptation. School engagement, as described above, does not adequately address school adaptation. We argue that school engagement is one component of a child's adaptation in school, but is not as comprehensive, does not necessarily take into account the perspectives of multiple important stakeholders, and artificially combines aspects of school adaptation that may be uniquely important. While school engagement is viewed as a single construct, we approach school adaptation as encapsulating a broader picture of youth's success in school. School adaptation includes a constellation of potentially important indicators. By taking a higher-level approach to school adaptation, we hope to gain a better understanding of the experiences of youth in school, the challenges they face, the successes they experience, what that means for their overall adaptation, and how to support their optimal development. Second, the extant research has not explored profiles of student adaptation among youth who are involved with the child welfare system, potentially missing a population in which a strong connection to school is of the utmost importance. Third, there is a dearth of research exploring the association between school adaptation and youth mental health, thus ignoring an important dimension of youth wellbeing and adaptation. 


\begin{abstract}
Aims
The literature to date has mostly focused on school factors as outcomes that demonstrate youth resilience and level of risk. In contrast, very little research has explored how the connection to school impacts the known relationships between adversity and youth outcomes. This project sought to shed light on the role of schools in conferring risk or resilience for youth in contact with the child welfare system, with regard to their mental health. The overall aims of this project are to (1) improve our conceptualization of school adaptation, with particular attention to individual variation along multiple dimensions of school adaptation, (2) examine the relationship of school adaptation to important child welfare indicators, and (3) explore the impact of school adaptation on youth mental health.
\end{abstract}

\title{
Aim 1: Identification of profiles of school adaptation among youth involved
}

with child welfare services. The first aim of this study was to examine the school adaptation of children and adolescents in a comprehensive, holistic, and nuanced way that takes into account a variety of factors related to the school context. Previous research has largely relied on a single indicator of well-being at school, such as academic achievement as assessed by performance measures, grade point average from school records, completion of milestones like graduation, or school engagement as reported by youth. Other research has combined multiple, potentially meaningful components of school adaptation into a single measurement, or into two, three or four-dimensional models of school adaptation. By doing so, meaningful specificity regarding components of school adaptation may be lost. We hoped to "unscramble the eggs" (Oberski, 2016) of school 
adaptation and gain back the specificity that is lost in composite variables, while maintaining the breadth of school indicators that is lost by using single indicators.

We are not aware of any research that has examined school adaptation, specifically among youth involved with child welfare services, in this comprehensive way. In this study, we utilized the constellations of indicators of school adaptation to understand the varied representations of school adaptation for youth who are involved with child welfare services. It is easy to imagine a student who is on grade level in reading and math but may not feel connected to school or may be experiencing behavioral difficulties. It is also feasible to imagine a child who loves school and feels connected to peers and teachers, but has poor attendance rates, test scores, and grades, because of outside factors beyond their control. We hoped to discover the hidden groups reflected by these variables and determine if common profiles exist among the multiple ways of measuring success and connection in the school context. We predicted that a positive profile of school adaptation, which has the potential to protect youth from some of the negative impacts of life stressors, includes aspects of teacher perception, student behavior, cognitive appraisal, demonstrable academic achievement, and feelings of belonging and self-efficacy. We predicted that profiles of school adaptation would be more complicated than simply universally high, moderate, and low adaptation, and that a range of indicators would distinguish these groups.

\section{Aim 2: Predictors of school adaptation profiles among youth involved with}

child welfare services. A second aim of this study was to discern factors that predict school adaptation profiles. While extant research has explored the associations between 
individual indicators of school adaptation and risk factors, such as elevated absenteeism rates for children living with neglectful caregivers, there is limited understanding of the relationship between identified risk factors and the broader picture of school adaptation. We predicted that profiles of school adaptation would vary by demographic and child welfare specific differences including youth race/ethnicity, gender, age, alleged type of maltreatment experienced by the youth, substantiation of the maltreatment, and severity of maltreatment experienced. Specifically, our predictions aligned with the existing literature that poorer school adaptation would be associated with older age (Janosz, Achambault, Morizot, Pagani, 2008), male gender (Appleton, Christenson, \& Furlong, 2008; Furrer \& Skinner, 2003), racial/ethnic minority status (Johnson, Crosnoe, \& Elder Jr, 2001), and experience of neglect (Oh \& Song, 2018). While the research on dimensions of maltreatment and school outcomes are mixed (McGuire \& Jackson, 2018), with some studies finding no association (Coohey, Renner, Hua, Zhang, \& Whitney, 2011), and other studies finding a significant association (Daignault \& Hébert, 2008), we predicted that poorer school outcomes would be associated with substantiation of maltreatment and more severe maltreatment.

\section{Aim 3: Examining the role of school adaptation in buffering the effects of} child welfare indicators of maltreatment on mental health outcomes. A wealth of research has demonstrated poorer mental health outcomes of youth involved in child welfare services and the negative impacts of experiencing maltreatment on mental health functioning. The third aim of this project was to explore the role of school adaptation in the relationship between child welfare indicators of maltreatment and mental health 
outcomes for youth involved with child welfare services. We predicted that youth who demonstrate positive school adaptation would demonstrate more resilience in the face of substantiated maltreatment and more severe maltreatment, with regard to their mental health. We predicted that youth who have low levels of school adaptation would be at greater risk of succumbing to the effects of maltreatment and experience poorer mental health. An important purpose of this study was to understand the relative contributions to mental health made by school adaptation versus aspects of child welfare involvement. We predicted that school adaptation would independently explain youth mental health, even when taking child welfare indicators into account. We also predicted that school adaptation would buffer the impact of maltreatment on youth mental health functioning. Specifically, we hypothesized that maltreatment severity would have a more substantial impact on mental health functioning long-term in the context of suboptimal school adaptation, as these youth do not benefit from this layer of protection. We also hypothesized that for youth who experience the benefits of a strong connection to school and the resilience conferred by a more positive profile of school adaptation, the relative impact of child welfare indicators of maltreatment on mental health would be reduced. 


\section{CHAPTER TWO: METHOD}

\section{The National Survey of Child and Adolescent Well-Being (NSCAW)}

The first National Survey of Child and Adolescent Well-Being (NSCAW-I) is a longitudinal study that followed a cohort of 5,501 infants, children, and adolescents who were the subjects of investigations by child welfare services during a 15-month period starting in October of 1999. Children between the ages of zero and 14 years of age, at the initial wave of data collection, were recruited from 97 counties across the United States to create a national probability sample.

\section{Caseworker Measures}

Demographics. Demographic information regarding youth age, gender, and race/ethnicity utilized derived variables from NSCAW which incorporated reports from two or more respondents including youth, caregivers, and caseworkers.

Maltreatment Classification Scale. Child welfare service caseworkers completed a modified version of the Maltreatment Classification Scale (MCS; Manly, Cicchetti, \& Barrett, 1994) which was used to assess multiple components of the alleged maltreatment experienced by the youth. The MCS is a commonly used scale in the literature and has consistently demonstrated good reliability and validity (Manly, Cicchetti, \& Barrett, 1994). 
Alleged type of maltreatment leading to investigation. The MCS was used to identify forms of maltreatment allegedly experienced by youth which resulted in the investigation by child welfare services. Previous studies have reported that the MCS demonstrates interrater reliability for different maltreatment subtypes of .89 to .98 (Price $\&$ Glad, 2003). For youth in which multiple forms of alleged abuse or neglect were reported, caseworkers were asked to rate which form of maltreatment was most severe. For the purposes of this study, categories of alleged abuse or neglect were collapsed into investigations involving physical abuse, sexual abuse, emotional abuse, neglect (including not providing, failing to supervise, and abandonment), or "other" (including moral/legal maltreatment, educational maltreatment, exploitation, and other unspecified forms of maltreatment) as is consistent with much of the literature in the field.

Substantiation of maltreatment. Derived variables from NSCAW, which compiled child welfare service caseworker reports on the outcome of the investigation, were used to distinguish alleged experiences of maltreatment that were deemed as substantiated or other than substantiated (including allegations that were neither substantiated or indicated, and unfounded or ruled out).

Severity of maltreatment/Level of harm to child. Child welfare service caseworkers were asked, "Regardless of the outcome of the investigation, how would you describe the level of harm to the child? Would you say...?" Caseworkers were asked to choose one of four responses including none, mild, moderate, or severe. 


\section{Caregiver Measures}

Child Behavior Checklist. Youth mental health was measured using the Child Behavior Checklist (CBCL) from the Achenbach System of Empirically Based Assessment (ASEBA; Achenbach \& Rescorla, 2001). The CBCL has been used in thousands of studies and has demonstrated good reliability and validity (Achenbach \& Rescorla, 2001). This measure contains 113 items in which participants respond to how often behaviors are true for them using a Likert scale $(0=$ not true, $1=$ sometimes true, 2 $=$ often true). The CBCL was completed by available caregivers at Waves 1,3 , and 4 of data collection. The current study utilized standardized T-scores of the Total Problems Score.

\section{Teacher Measures}

Social Skills Rating System. The Cooperation scale from the Social Skills Rating System (SSRS; Gresham \& Elliot, 1990) Teacher Form was used to assess teacher rated classroom behavior. Teachers were asked to rate the student's behavior regarding use of classroom time, completion of assignments, following of directions, ignoring of peer distractions, and other behaviors reflecting in-class behavioral functioning. The SSRS asks teachers to rate behaviors as occurring never, sometimes, or very often. The SSRS has been shown to be a psychometrically sound instrument (Benes, 1995) and provides standard scores normed on a national sample of over 4,000 youth. Alpha coefficients for the cooperation scale were .92 for the child version and .93 for the adolescent version within this sample. 
Teacher-rated student behavior problems. Teachers were asked, "In this school year, has the student had any behavior or discipline problems at this school which resulted in the student's parents being sent a note or being asked to come in and talk with the teacher or principal?" and asked to respond Yes, No, or Don't know. If they responded Yes, then teachers were asked the follow up question, "Has this happened just once or more than once?" and asked to respond Once, More than once, or Don't know. Responses to these questions were scored such that scores of 0 reflected that the student had never gotten in trouble to this degree, scores of 1 reflected that it had happened one time, and scores of 2 reflected that the student had gotten in trouble to this degree multiple times.

Attendance. Teachers were asked to report how many school days were missed by the student in the academic school year.

Teacher Report Form. Teacher rated academic achievement was measured using components of the Teacher Report Form (TRF) from the Achenbach System of Empirically Based Assessment (ASEBA; Achenbach \& Rescorla, 2001). The TRF is a parallel form to the CBCL and asks educators to rate the performance of the student in each academic subject taught as Far below grade, Somewhat below grade, At grade level, Somewhat above grade, or Far above grade. Teacher reports of academic achievement were averaged to create a composite rating of teacher rated academic achievement. Overall, psychometric properties for this measure are considered very good (ASEBA; Achenbach \& Rescorla, 2001). The TRF has demonstrated acceptable test-retest reliability and internal consistency but questionable inter-rater reliability. The TRF has demonstrated construct and criterion validity among clinical and nonclinical samples of 
youth (Thorvaldsen, 2005). Alpha coefficients for this variable within this sample ranged from .81 to .94 , depending on the number of subjects rated by the teacher.

\section{Youth Measures}

Woodcock-Johnson Mini-Battery of Achievement. Academic achievement was measured using the Woodcock-Johnson Mini-Battery of Achievement (MBA;

Woodcock, McGrew, \& Werder, 1994). The MBA can be administered in 20-30 minutes, was completed at Waves 1, 3, and 4 of data collection, and provides standardized scores of achievement $(M=100, S D=15)$ in both reading and math. The MBA has demonstrated concurrent validity with other instruments used to measure academic achievement and has been shown to have good internal consistency and test-retest reliability (Woodcock, McGrew, \& Werder, 1994).

\section{School Engagement Questionnaire from the Drug-Free Schools and}

Communities Act Survey. Participants in NSCAW from 6 years of age and older completed a measure of student engagement from the Drug-Free Schools and Communities Act Survey (Dowd et al., 2004). This measure included 11 items assessing youth's feelings about school, perceived ability to succeed in school, and behavioral measures of engagement. Youth rated each item as Never, Sometimes, Often, or Almost Always. Items with a negative valence were reverse scored, and raw scores were converted into Z-scores to be used in subsequent analyses. Limited information is available regarding the psychometric properties of this measure, but it is commonly used to assess aspects of student reported school engagement (Bender, 2012; Leonard \& Gudiño, 2016), and has demonstrated acceptable reliability (Tyler, Johnson, \& 
Brownridge, 2008) and convergent validity with measures of academic achievement (Leonard, Stiles, \& Gudiño, 2016). Preliminary analysis, including bivariate correlations and exploratory latent profile analyses revealed that school engagement item number 4 ("How often do you find the schoolwork too hard to understand?") and school engagement item 6 ("How often do you fail to complete or turn in your assignments?") did not correlate with other indicators as expected and did not distinguish latent profiles of school functioning. These items were conceptually redundant with other indicators and added unnecessary noise to the model, thus they were excluded from the primary analyses. While the 9 items used were entered into the latent profile analysis separately, the alpha coefficient between these items was .73 within this sample. This questionnaire was completed at Waves 1, 3, and 4. Specific items and the theoretical constructs they measure are described below.

Student rated student-teacher relationship. Item " 8 . How often do you get along with your teachers?" was used to assess youth rated student-teacher relationships.

Student rated peer relationships. Item "11. How often do you get along with other students?" was used to assess youth rated peer relationships.

Emotional engagement. Emotional engagement with school was measured using items "1. How often do you enjoy being in school?" and "2. How often do you hate being in school?" While these two items are conceptually similar, they demonstrated only a moderate correlation $(-0.46, p<.01)$ and thus were entered into the latent profile analysis separately. 
Behavioral engagement. Behavioral engagement with school was measured using items "3. How often do you try to do your best work in school?" "7. How often do you get sent to the office, or have to stay after school, because you misbehaved?" "9. How often do you listen carefully or pay attention in school?" and "10. How often do you get your homework done?" Bivariate correlations between these four items ranged from $0.18(p<.01)$ to $0.37(p<.01)$. Given these lower correlations, the four items were entered into the latent profile analysis separately.

Cognitive engagement. Cognitive engagement was measured using item "5. How often do you find your classes interesting?"

\section{Procedure}

Wave 1 of data collection was completed within 2-6 months of the completion of the investigation by child welfare services. Wave 3 was completed at 18 months after the investigation, and Wave 4 was completed at 36 months after the investigation. Approval for all NSCAW procedures was obtained from the Research Triangle Institute's Institutional Review Board (IRB), four states, and five additional NSCAW consortium institutions. The current study utilized data from interviews with youth, caseworkers, and caregivers. Consent for participation of youth was obtained from the person with the legal authority to do so, and youth participants provided assent. Caregivers and caseworkers consented for their own participation. The secondary analysis of this data, for the purposes of the current study, was approved by the University of Denver IRB. 


\section{Data Analysis}

Complex survey design. NSCAW utilized a two-stage stratified design which intentionally over sampled for infants, sexual abuse cases, and cases receiving ongoing services after investigation. A two-stage stratified design allowed for over sampling using first stage strata and second stage domains. Sampling weights were used to yield national estimates for the population of children involved with child welfare services. Weights were calculated for each participant by the NSCAW Research Group and are included in NSCAW data sets. Analyses were conducted using SPSS Complex Samples, Version 22 (IBM, 2013), and MPlus (Version 6; Muthén \& Muthén, 2010) to account for the complex survey design of NSCAW.

Preliminary analyses. First, descriptive statistics, including ranges, means, and standard deviations, were calculated for all control and outcome variables (see Table 1). All variables to be included in the latent profile analysis are described in Table 2, including how the construct was measured, the respondent providing the information, measures used, and items. Next, bivariate correlations (see Table 3) and analyses of variance (ANOVAs) were completed to assess potential relationships between variables to be included in the latent profile analysis. Missing data analyses were conducted to determine if specific variables predicted overrepresentation of missing data.

\section{Aim 1: Identification of profiles of school adaptation among youth involved}

with child welfare services. To test our prediction that multiple aspects of school adaptation are separable components of the broader construct, and may help distinguish different groups of children experiencing different types and levels of school adaptation, 
latent profile analysis was used to categorize youth into profiles which capture the relationships between these variables. Latent profile analysis is a technique used to recover hidden groups from observed data (Oberski, 2016). Latent profile analysis is used to reduce large numbers of variables into a few easily interpretable subgroups. This analysis included indicators at Wave 1, including student-rated emotional engagement, behavioral engagement, cognitive engagement, peer relationships, and student-teacher relationships; academic achievement as measured by performance assessments; and teacher-rated academic competence, classroom behavior, frequency of parent contact regarding student behavior problems, and attendance. All variables were converted to Zscores $(M=0, S D=1)$ before being entered into the latent profile analysis. Good model fit was determined by lower values on the Akaike Information Criterion (AIC; Akaike, 1987), Bayesian Information Criterion (BIC; Schwartz, 1978), and Sample Size Adjusted Bayesian Information Criterion (SABIC; Scolve, 1987), as well as improvement of the models over the previous model as indicated by a statistically significant Lo-MendellRubin Likelihood Ratio Test (LMR-LRT; Lo, Mendell, \& Rubin, 2001).

\section{Aim 2: Predictors of school adaptation profiles among youth involved with}

child welfare services. The second aim of this study was to test for associations between school adaptation profiles and relevant variables that may be related to school adaptation, including child welfare indicators (such as alleged type of maltreatment, substation of maltreatment, caseworker rated severity of maltreatment) race/ethnicity, gender, and age. We predicted that known risk factors for poor mental health and academic outcomes at 
Wave 1 would be related to poorer initial school adaptation. This hypothesis was evaluated using multinomial logistic regression analysis.

\section{Aim 3: Examining the role of school adaptation in buffering the effects of} child welfare indicators of maltreatment on mental health outcomes. The third aim of this study was to determine whether school adaptation moderates the relationship between child welfare indicators of maltreatment and mental health. We predicted that latent profiles of school adaptation would significantly predict later mental health symptomology and moderate the relationship between child welfare indicators of maltreatment and mental health. A hierarchical regression analysis was conducted to test for main effects of school adaptation profiles on mental health at Wave 4, after controlling for mental health at Wave 1. To test for moderation effects, interaction terms of school adaptation profiles and maltreatment severity were generated and used to predict mental health symptomology. Step 1 of the model included mental health symptomology at Wave 1, race/ethnicity, substantiation of maltreatment, alleged type of maltreatment experienced, and caseworker rated severity of maltreatment. The White racial group and the Neglect alleged type of maltreatment group were used as reference groups, given that these were the largest groups in the sample. School adaptation profile membership was added in Step 2 of the model, and interaction terms of school adaptation profile membership dummy codes with caseworker rated severity of maltreatment were added in Step 3 of the model. 


\section{CHAPTER THREE: RESULTS}

\section{Descriptive Statistics and Preliminary Analyses}

Descriptive statistics are presented in Table 1. Overall, this sample was diverse in terms of age $(\min .=4, \max .=16, M=9.96, S E=.06)$, gender $(52.8 \%$ female, $47.2 \%$ male), and race/ethnicity (45.7\% White, 29.6\% Black, 16.5\% Hispanic, and 7.9\% other). The sample also varied in terms of alleged type of maltreatment that led to the investigation by child welfare services $(25.7 \%$ physical, $18.0 \%$ sexual, $7.7 \%$ emotional, $41.8 \%$ neglect, and $6.8 \%$ other), substantiation of maltreatment (60.2\% substantiated, $39.8 \%$ other than substantiated), and the caseworker reported severity of maltreatment experienced by the youth ( $24.2 \%$ none, $29.0 \%$ mild, $31.1 \%$ moderate, and $15.7 \%$ severe). This sample also varied widely with regards to all indicators of school adaptation. Of note, this sample had missed an average of 10.51 days $(S D=13.97)$ of school during the academic year, demonstrating a considerable amount of missed school and had mean WJ scores about one half standard deviation below the population mean, as well as considerable variability $(M=93.15, S D=20.22)$. On average, teachers rated this sample as "Somewhat below grade" to "At grade level" with regards to academic functioning. With regards to mental health, average caregiver ratings of combined internalizing and externalizing symptomology was somewhat elevated compared to population samples, with $27.62 \%$ of the sample falling in the "at-risk" range for mental health problems and 
$22.99 \%$ falling in the clinically significant range at Wave 1 , as well as $26.10 \%$ of the sample falling in the "at-risk" range for mental health problems and $18.16 \%$ falling in the clinically significant range at Wave 4.

As expected, there were many significant correlations between indicators of school adaptation ranging from .05 to $.50(p<.05)$. Bivariate correlations for indicators of school adaptation are displayed in Table 3. Given that most bivariate correlations between the 14 indicators of school adaptation ranged from weak to moderate, and the indicators were conceptually distinct and meaningful, the decision was made to include each of the 14 indicators in the latent profile analysis as separate variables, and not combine or average indicators. As described above, three potential indicators of school adaptation, including the Social Loneliness and Dissatisfaction Questionnaire, school engagement item number 4 ("How often do you find the schoolwork too hard to understand?") and school engagement item 6 ("How often do you fail to complete or turn in your assignments?"), were excluded from the latent profile analysis as they did not correlate with other indicators as expected, did not distinguish latent profiles of school adaptation, were conceptually redundant with other indicators, and added unnecessary noise to the model. Exploratory analyses with 14 to 17 indicators revealed similar latent profile analysis results in terms of the appropriate number of profiles and differences between profiles. ANOVAs revealed that all 14 indicators included in the latent profile analysis demonstrated significant between groups variance $(p<.001)$. 


\section{Missing Data Analyses}

The sample size included in each analysis varied by aim. Of the 5,501 youth in NSCAW, 2,668 youth had at least partial data for the school adaptation latent profile analysis in Aim 1. Of the 2,833 youth excluded from Aim 1, 2,571 (90.8\%) were excluded due to being too young to be included in our sample as they did not complete appropriate measures that only 5-16 year-olds completed. Only 262 youth $(9.2 \%$ of excluded youth or $4.8 \%$ of the total sample) were old enough to be included in these analyses, but were excluded due to missing data. Of these 2,668 youth included in the latent profile analysis, $90.7 \%(n=2,421)$ had data for 7 or more of the 14 variables included in the analysis, demonstrating that the vast majority of the included sample had data for many indicators of school adaptation. Of these 2,668 youth, 2,425 had data needed for the multinomial logistic regression in Aim 2, and 1,987 youth had all data needed for the regression analyses in Aim 3. Of the sample included in the latent profile analysis, only 243 youth $(9.1 \%)$ were excluded from Aim 2 due to missing data. Of the sample included in the latent profile analysis, 681 youth $(25.5 \%)$ were excluded from Aim 3 due to missing data. This is not surprising given that Aim 3 was the only aim that utilized longitudinal data as it incorporated caregiver reports of mental health at Wave 4. It is important to note that only $84.02 \%$ of the original sample had caregiver interviews at Wave $4(\mathrm{n}=4,622$ vs. $\mathrm{n}=5,501$ at Wave 1$)$, so this rate of missing data is likely due in large part to retention rates at Wave 4.

Given the larger proportion of excluded youth for missing data for Aim 3, missing data analyses were completed comparing the 681 youth excluded from aim 3 for missing 
data and the other 1,987 included in all 3 aims of data analysis. T-tests revealed that youth with missing data were older $(M=10.15, S D=3.01$ vs. $M=9.89, S D=2.84, p=$ $.001)$ and were rated as experiencing less severe maltreatment by caseworkers $(M=2.35$, $S D=.97$ vs. $M=2.39, S D=1.03, p=.023)$. There was a marginally significant difference in substantiation of maltreatment such that $23.0 \%$ of those in the "other than substantiated" group were excluded for missing data, while $26.1 \%$ of those in the substantiated group were excluded for missing data $\left(\chi^{2}=3.24, p=.07\right)$. Significant differences in rates of exclusion were found by race $\left(\chi^{2}=34.56, p<.001\right)$. Data were missing at a significantly higher rate for the "other" racial group compared to the overall sample $(35.4 \%$ vs. $24.9 \%, p<.001)$ and at a significantly lower rate for the white racial group compared to the overall sample $(22.1 \%$ vs. $24.9 \%, p=.005)$. There were no significant differences between those included in all three aims versus those excluded from aim 3 with regards to gender, school adaptation profile membership, or alleged type of maltreatment experienced.

\section{Aim 1: Identification of Profiles of School Adaptation Among Youth Involved with Child Welfare Services.}

Determining model fit and the best number of profiles. Fourteen indicators of school adaptation (as displayed in Table 3) at Wave 1 were included in the latent profile models, including nine items from the youth self-report school engagement questionnaire, teacher rated academic performance, combined math and reading Woodcock-Johnson academic achievement scores, teacher rated on-task classroom behaviors from the SSRS, teacher rated frequency of behavioral difficulties resulting in contact with parents, and 
teacher rated attendance. Models consisting of one through ten profiles were estimated as displayed in Table 4. The four-profile solution was supported by all three information criterion indices (AIC, BIC, and SABIC) as better fitting the data than models with fewer profiles. Entropy, or the quality of classification, was also higher for the four-profile model than for models with fewer profiles. Some statistics, including AIC, BIC, SABIC, and entropy, potentially supported the interpretation of up to nine profiles, but the best log-likelihood value was not replicated for models with more profiles, even when using very high starting values, suggesting a local maxima and poor fit of these models for the data. These models with additional profiles also yielded very small profile sizes. The four-profile model $(\log L=-36100.07, A I C=72346.13, B I C=72776.04, S A B I C=$ 72544.09, $L M R-L R T=1396.25, p=0.66$, Entropy $=0.83$ ) was determined to be the most conceptually meaningful and statistically sound of the options.

Description of the profiles. Standardized estimated within-profile means for these four profiles and significant differences between profiles are displayed in Table 5. A graph of the standardized within-profile means for each variable is displayed in Figure 1. Table 6 displays within profile means and percentages for demographic, child welfare, and mental health variables. Profiles are interpreted by profile size from largest to smallest. Profile 4, the largest of the profiles, representing $50.1 \%$ of the total sample, demonstrated significantly better scores on 12 indicators of school adaptation compared to all three other profiles. The only indicators on which profile 4 did not do significantly better than all three other profiles were student reported frequency of being sent to the office regarding behavior problems, on which profiles 1 and 4 were not significantly 
different as the frequency was low for both groups (Profile $1 M=1.00$ vs. Profile $4 M=$ 1.00), and days absent during the academic year, in which there were not significant differences between profiles except that Profile 2 had significantly more absences than Profile 4 (Profile $2 M=13.66$ vs. Profile $4 M=8.71, p<.001$ ), but Profile 4 was not significantly different from Profiles 1 or 3. Given the positive adaptation across indicators, Profile 4 will be referred to as the "high overall adaptation group." Profile 2, which was the second largest of the profiles (22.9\% of total sample) demonstrated moderate levels of school adaptation across most indicators. Specifically, Profile 2 demonstrated significantly better adaptation than Profiles 1 and 3 with regards to getting along with other students (Profile $2 M=2.99$ vs. Profile $1 M=2.70, p<.001$; Profile $2 M=2.99$ vs. Profile $3 M=2.72, p<.01$ ), getting along with teachers (Profile 2 $M=3.04$ vs. Profile $1 M=2.76, p<.001$; Profile $2 M=3.04$ vs. Profile $3 M=2.60, p<$ .001 ), finding classes interesting (Profile $2 M=2.63$ vs. Profile $1 M=2.10, p<.001$; Profile $2 M=2.63$ vs. Profile $3 M=2.41, p<.05$ ), trying their best on schoolwork (Profile $2 M=3.31$ vs. Profile $1 M=3.03, p<.001$; Profile $2 M=3.31$ vs. Profile $3 M=$ $3.06, p<.001$ ), paying attention (Profile $2 M=3.02$ vs. Profile $1 M=2.82, p<.01$; Profile $2 M=3.02$ vs. Profile $3 M=2.64, p<.001$ ), completing homework (Profile $2 M$ $=3.04$ vs. Profile $1 M=2.83, p<.001$; Profile $2 M=3.04$ vs. Profile $3 M=2.77, p<$ .001 ), and lower rates of hating school (Profile $2 M=2.13$ vs. Profile $1 M=2.57, p<$ .001 ; Profile $2 M=2.13$ vs. Profile $3 M=2.34, p<.05$ ). Profile 2 also reported significantly higher rates of enjoying school compared to Profile 1 (Profile $2 M=2.81$ vs. Profile $1 M=2.06, p<.001$ ) and significantly lower rates of student reported being sent 
to the office regarding behavior compared to Profile 3 (Profile $2 M=2.00$ vs. Profile $3 M$ $=3.40, p<.001)$. Interestingly, there were several areas in which Profile 2 demonstrated significantly worse school adaptation than Profile 1, including worse teacher rated classroom behavior (Profile $1 M=-.22$ vs. Profile $2 M=-.47, p<.05$ ), higher rates of teacher reported frequency of contacting parents regarding behavior problems compared to Profile 1 (Profile $2 Z=-.62$ vs. Profile $1 Z=-.01, p<.001$ ), and higher rates of student reported being sent to the office regarding behavior problems (Profile $1 M=1.00$ vs. Profile $2 M=2.00, p<.001$ ). Profile 2 will therefore be referred to as the "moderate overall adaptation with somewhat poor behavior group."

With regards to the smallest two profiles of school adaptation, Profile 1 (17.8\% of the sample) and Profile 3 (9.2\% of the sample) differed in some significant ways. As illustrated in Figure 1, Profiles 1 and 3 had lower levels of school adaptation than Profiles 2 and 4 on many indicators, but separated from each other in some important ways. Profile 1 outperformed Profile 3 with regards to paying attention (Profile $1 M=2.82$ vs. Profile $3 M=2.64, p<.05$ ), teacher reported frequency of contacting parents regarding behavior problems (Profile $1 M=-.01$ vs. Profile $3 M=-.59, p<.001$ ), and student reported rates of being sent to the office for behavior problems (Profile $1 M=1.00 \mathrm{vs.}$ Profile $3 M=3.40, p<.001)$. At the same time, Profile 3 outperformed Profile 1 with regards to enjoying school (Profile $1 M=2.06$ vs. Profile $3 M=2.65, p<.001$ ), finding classes interesting (Profile $1 M=2.10$ vs. Profile $3 M=2.41, p<.001$ ), and lower rates of hating school (Profile $1 M=2.57$ vs. Profile $3 M=2.34, p<.01$ ), though these indicators were not as high as the moderate overall adaptation with somewhat poor 
behavior group or the high overall adaptation group as described above (except that the difference between Profiles 2 and 3 was not statistically significantly different with regards to enjoying school). Profile 3 will therefore be referred to as the "low overall adaptation with poor behavior group" and Profile 1 will be referred to as the "low overall adaptation with good behavior and low emotional/cognitive engagement group."

\section{Aim 2: Predictors of School Adaptation Profiles Among Youth Involved with Child Welfare Services.}

Initial pairwise comparisons revealed significant between profile differences among variables. For example, the low overall adaptation with good behavior and low emotional/cognitive engagement group was significantly less likely than the high overall adaptation group to have been investigated for sexual abuse $(14.1 \%$ vs. $18.2 \%, B=-$

$0.545, p=.026)$ or emotional abuse $(4.9 \%$ vs. $7.9 \%, B=-.777, p=.011)$. The moderate overall adaptation with somewhat poor behavior group was significantly more likely to include children in the Black racial group than the high overall adaptation group $(33.9 \%$ vs. $26.4 \%, B=0.510, p=0.019)$. The low overall adaptation with poor behavior group was significantly less likely than the high overall adaptation group to include youth with "other than substantiated" reports of abuse or neglect group (35.8\% vs. $40.4 \% B=-.363$, $p=.040)$.

Subsequently, we took a multivariate approach to examine associations between profiles and potential predictors of profile membership. Fit statistics indicate that the multinomial logistic regression model fit the data well. The Pearson $\chi^{2}$ value of the multinomial logistic regression was $3681.861(d f=3771, p=.848)$ and the Deviance 
$\chi^{2}$ value was $3362.291(d f=3771, p=1.000)$. Non-significance of these tests suggests that the model fits the data well (Petrucci, 2009). Additionally, the final log likelihood value was $4261.854\left(\chi^{2}=203.188, d f=36, p<.001\right)$ suggesting that the variables in this model significantly improve the model over the intercept alone.

Table 7 includes the likelihood ratio tests for each of the variables included in the multinomial logistic regression. Results indicate that alleged abuse type experienced, substantiation of maltreatment, and child race/ethnicity did not significantly predict school adaptation profile membership overall. Caseworker rated maltreatment severity $\left(\chi^{2}=7.889, p=.048\right)$, child age $\left(\chi^{2}=67.841, p<.001\right)$ and child gender $\left(\chi^{2}=97.541, p<\right.$ .001) significantly predicted profile membership. Compared to the high overall adaptation group $(\overline{\mathrm{x}}=9.52)$, all other profiles of school adaptation were significantly older (Profile 1: $\overline{\mathrm{x}}=10.27, B=.094, p<.001$; Profile 2: $\overline{\mathrm{x}}=10.36, B=.117, p<.001$; Profile $3: \overline{\mathrm{x}}=10.73, B=.162, p<.001)$. Compared to the high overall adaptation group $($ male $=39.2 \%)$, all other profiles of school adaptation were significantly more likely to include males than females (Profile 1: male $=52.0 \%, B=-.365, p=.002$; Profile 2: male $=60.5 \%, B=-.904, p<.001 ;$ Profile 3: male $=61.0 \%, B=-1.067, p<.001)$. While caseworker reported severity of maltreatment did significantly predict profile membership overall, pairwise comparisons revealed there was only a marginally significant difference between level of caseworker reported severity of maltreatment between the low overall adaptation with poor behavior group $(\overline{\mathrm{x}}=2.32)$ and the high overall adaptation group $(\overline{\mathrm{x}}=2.40, B=-.153, p=.077)$, and no other pairwise comparison were significant regarding caseworker reported severity of maltreatment 
predicting profile membership. Table 8 displays parameter estimates for profiles 1,2 , and 3.

\section{Aim 3: Examining the Role of School Adaptation in Buffering the Effects of Child Welfare Indicators of Maltreatment on Mental Health Outcomes.}

Table 9 displays ANOVAs examining mental health functioning at Wave 4 by school adaptation profile. When not controlling for other covariates, the high overall adaptation group experienced significantly lower caregiver reported mental health symptomology than all three other groups. The low overall adaptation with poor behavior group experienced significantly higher caregiver reported mental health symptomology than all three other groups. The low overall adaptation with good behavior and low emotional/cognitive engagement group and the moderate overall adaptation with somewhat poor behavior group were not significantly discrepant from each other with regard to caregiver reported mental health symptomology.

Table 10 displays the unstandardized beta-coefficients $(B)$, standardized betacoefficients $(\beta)$, and $t$ values for the model predicting mental health outcomes at wave 4 . Values in Table 10 come from Step 2 of the model, except for the values for the interaction terms, which come from Step 3 of the model. Mental health symptomology at Wave $1(\beta=.532, p<.001)$ and caseworker reported severity of maltreatment $(\beta=.052$, $p=.017)$ significantly predicted mental health symptomology at Wave 4. Race/ethnicity, substantiation of abuse or neglect, and alleged type of maltreatment did not significantly predict mental health symptomology at Wave 4 when controlling for other relevant covariates. As predicted, school adaptation profile membership marginally to 
significantly predicted mental health symptomology at Wave 4 (Profile 1: $\beta=.034, p=$ .086 ; Profile 2: $\beta=.059, p=.003$; Profile 3: $\beta=.065, p=.001)$. Membership in the low overall adaptation with good behavior and low emotional/cognitive engagement group was associated with a 1.14 increase in T-score on the total mental health problems index of the CBCL compared to the high overall adaptation group. Membership in the moderate overall adaptation with somewhat poor behavior group was associated with a 1.79 increase in T-score on the total mental health problems index of the CBCL compared to the high overall adaptation group. Membership in the low overall adaptation with poor behavior group was associated with a 2.84 increase in $\mathrm{T}$-score on the total mental health problems index of the CBCL compared to the high overall adaptation group. Including school adaptation profile membership in the model predicting mental health at Wave 4 did significantly increase the variance accounted for by the model $\left(\Delta R^{2}=.014, \Delta F=\right.$ $13.42, p<.001)$. The interactions of school adaptation profile membership dummy codes and caseworker reported severity of maltreatment did not significantly predict mental health symptomology at Wave 4 (Profile $1 \mathrm{X}$ Severity of maltreatment: $\beta=.034, p=$ .510 ; Profile $2 \mathrm{X}$ Severity of maltreatment: $\beta=.056, p=.263$; Profile $3: \beta=.043, p=$ .337). Including the interaction terms in the model predicting mental health at Wave 4 did not significantly increase the variance accounted for by the model $\left(\Delta R^{2}<.001, \Delta F<\right.$ $.001, p=1.00)$. 


\section{CHAPTER FOUR: DISCUSSION}

This study utilized data from youth ages 4 to 16 years of age, their caregivers, teachers, and caseworkers, who participated in the National Survey of Child and Adolescent Well-Being (NSCAW-I) following an investigation by child welfare services for alleged maltreatment. The goals of this study were to understand the school adaptation of these high-risk youth in a holistic and student-centered way, as well as the relationships of school adaptation with relevant risk factors and mental health outcomes. We hypothesized that school adaptation would include a range of related but separate indicators that would distinguish youth into meaningful groups, that membership in these groups would be related to known risk factors in this population, including substantiation of maltreatment, severity of maltreatment, and type of maltreatment experienced, and that school adaptation groups would predict later mental health functioning. These hypotheses were tested using latent profile analysis of many indicators of school adaptation, multinomial logistic regression predicting profile membership by known risk and demographic variables, and hierarchical regression predicting mental health. Support for hypotheses was mixed.

It is also important to draw attention to some illuminating findings and patterns that were uncovered in this study. First, it is not surprising that this group of youth experienced ongoing challenges both in and out of school. The average youth in this 
sample experienced mental health symptomology approaching the "at-risk" range at Wave 1 near the onset of the investigation of child welfare services, had been absent from school over 10 days since the beginning of the year, had WJ scores nearly half a standard deviation below the population mean, and endorsed hating school "sometimes." Given that every youth in this sample was involved with child welfare services due to alleged maltreatment, it is not surprising that they appeared to be experiencing additional difficulties. This level of risk is exactly why understanding the school adaptation of this sample, and its potential impact on other aspects of functioning, such as mental health, was so intriguing and important.

\section{Aim 1: Identification of Profiles of School Adaptation Among Youth Involved with Child Welfare Services.}

Aim 1 examined the school adaptation of youth involved with child welfare services by incorporating student and teacher reports of a variety of indicators, including feelings about school, interest in classes, relationships with teachers and peers, classroom behavior, academic performance, performance on standardized achievement tests, attendance, and frequency of getting into trouble at school, simultaneously. Consistent with our hypotheses, latent profile analysis revealed four separate profiles of school adaptation within this sample, which were more nuanced than simply high and low adaptation groups, and had significant differences across a range of indicators. The largest profile, described as the "high overall adaptation group," represented $50.1 \%$ of the sample and demonstrated adequate to strong adaptation across all indicators of school adaptation. This group enjoyed better school adaptation than the other three groups on 
almost all indicators of school adaptation with few exceptions. On one hand, it may be surprising that roughly half of the sample fit into this group, given the many risk factors associated with involvement with the child welfare system and the wealth of research demonstrating the negative impacts on school adaptation as outlined above. On the other hand, one might expect more of the sample to demonstrate adequate levels of school adaptation, given that even in the face of maltreatment, a large portion of youth demonstrate resilience and experience normal development (Masten \& Wright, 2010). Regardless of expectations, it is troubling that only half of this sample demonstrated this level of school adaptation.

The second largest school adaptation profile found, which we described as the "moderate overall adaptation with somewhat poor behavior group" represented nearly a quarter of our sample. This group was unique in several ways. First, the moderate overall adaptation with somewhat poor behavior group demonstrated a significant downshift on all indicators of school adaptation when compared to the high overall adaptation group. Despite not functioning as well as the high overall adaptation group, this group did fare better than either of the low adaptation groups with regard to their relationships with peers and teachers, emotional engagement, cognitive engagement, and completion of homework, signifying that they were doing significantly better in the school context than some. While only statistically significantly different from the high overall adaptation group, the moderate overall adaptation with somewhat poor behavior group also had the highest rates of missed school days. Lastly, the moderate overall adaptation group demonstrated an interesting pattern with regard to behavioral functioning. Across all 
three indicators of school behavior, including teacher ratings of classroom behavior on the SSRS, teacher reported frequency of contacting parents regarding behavior problems, and student reported frequency of being sent to the office, the moderate overall adaptation group was significantly worse off compared to the high overall adaptation group and the low overall adaptation with good behavior and low emotional/cognitive engagement group. This group raises some important questions regarding what separates them from the high overall adaptation group, as well as the low overall adaptation groups. Perhaps this group would reach the school adaptation of the high overall adaptation group if their attendance and/or behavior problems were not barriers to school well-being. Or perhaps the moderate overall adaptation group would demonstrate even worse behavioral functioning, similar to that of the low overall adaptation group with poor behavior, if not for the buffering effect of relatively better relationships at school, cognitive engagement, and lower rates of "hating" school. While the possible causal relationship between functioning on specific indicators of school adaptation is beyond the scope of this study, future studies may be able to isolate ideal targets for intervention by pinpointing the key leverage points within school adaptation that are most likely to impact other areas of school adaptation.

The latent profile analysis also revealed two groups which demonstrated low overall school adaptation when compared to the high overall adaptation and moderate overall adaptation group, but with different areas of relative strengths and weaknesses. Profile 1, or the low overall adaptation group with good behavior and low emotional/cognitive engagement, representing an additional $17.8 \%$ of the overall sample, 
experienced the worst emotional/cognitive engagement with school, as indicated by their reports of enjoying school, hating school, and finding classes interesting, but demonstrated better behavioral engagement than the other low overall adaptation group, or even the moderate overall adaptation group, as indicated by teacher rated classroom behavior, teacher reported frequency of contacting parents regarding behavior problems, and student reported rates of being sent to the office. Simply put, this is a group who experienced poor school adaptation overall, does not feel an emotional connection or interest in school, but is not disruptive in the classroom and is not getting into trouble. It is easy to imagine that these youth may be the students who are struggling in school, but "fly under the radar," because they do not present as behavioral challenges for teachers. It is also interesting that this group, despite a lack of behavioral problems, demonstrated academic competence (as indicated by teacher rated academic performance and on standardized measures of academic achievement) similar to that of the two groups who did demonstrate behavioral problems. Clearly, behaving well is not enough to perform well academically or function within the school context, and other factors, including relationships, emotional engagement, and cognitive engagement, may be just as important determinants of success in the school context.

Lastly, the latent profile analysis revealed a small group (9.2\% of the sample) of individuals with low overall school adaptation across most indicators, but with significantly greater behavioral problems than the other groups. While this group was most similar overall to the other low overall adaptation group, they demonstrated behavioral functioning more similar to the moderate overall adaptation group with poor 
behavior, but with the addition of significantly higher rates of student reported being sent to the office. Again, the direction of causality is unknown. Is this group functioning poorly across the board because of behavior problems, are they having behavior problems because of their disconnect from school, or are they both the result of some unknown cause? It is clear that this group, while a minority of the sample, is experiencing significantly impaired adaptation at school.

One of the most substantive goals of the current study was to develop a more comprehensive understanding of the school adaptation among this unique population. This study demonstrated that the traditional methods of using single indicators as proxies for school adaptation, or averaging indicators into a single variable or few dimensions, do not sufficiently and accurately represent the relationship between youth and school. Not only did all 14 indicators of school adaptation have surprisingly low correlations, but all of these indicators helped separate out latent groups, many with significant differences between all groups. Additionally, some of the most commonly used indicators of school adaptation, such as attendance, standardized achievement scores, and teacher rated academic performance, demonstrated the least variability between profiles and provided the least information regarding where individuals best fit, further demonstrating that proxies may not adequately approximate the broader construct of school adaptation and that many indicators must be considered simultaneously to best understand the varied profiles of school adaptation. Clearly, many aspects of school adaptation represent separate and important parts of the picture of how youth interface with school. This study demonstrated that in a group in which only about half of youth experience optimal school 
adaptation, such as those involved with child welfare services, it is necessary to consider many different aspects of the influential relationship between youth and school, incorporate the perspectives of a range of stakeholders, and consider the multiple dimensions of how youth demonstrate engagement.

\section{Aim 2: Predictors of School Adaptation Profiles Among Youth Involved with Child Welfare Services.}

Aim 2 sought to understand the relationships between these profiles of school adaptation, demographic variables, and risk factors associated with involvement with the child welfare system. We hypothesized that race/ethnicity, gender, and age would significantly predict profile membership. We also predicted that profile membership would be predicted by the alleged type of maltreatment experienced by the youth, whether or not the alleged maltreatment was substantiated, and caseworker reported severity of maltreatment.

Not surprisingly, we found that girls were more likely than boys to be in the highest overall adaptation group. This finding is consistent with our predictions and the existing literature showing that girls generally demonstrate higher levels of school engagement than boys (Appleton, Christenson, \& Furlong, 2008; Furrer \& Skinner, 2003). Also consistent with our predictions, we found that older youth were less likely than younger youth to be in the high overall adaptation group. While the literature is somewhat mixed regarding age and school engagement, several studies indicate that school engagement is a mostly stable construct, but declines slightly with development (Janosz, Achambault, Morizot, Pagani, 2008), and that older age is associated with lower 
school engagement among children in the child welfare population (Leonard \& Gudiño, 2016). Interestingly, we found that race/ethnicity did not significantly predict school adaptation profile membership in multivariate analyses, although one significant bivariate difference was found in that the moderate overall adaptation with somewhat poor behavior group was more likely to include Black youth than the high overall adaptation group. While racial differences have been found in school engagement in past research when examining the general student population (Johnson, Crosnoe, \& Elder Jr, 2001; Konold, Cornell, Shukla, \& Huang, 2017), perhaps these differences are less salient among a sample comprised solely of the high-risk group of youth involved with child welfare services.

Regarding child welfare indicators, we found that alleged type of abuse investigated and substantiation of maltreatment did not significantly predict school adaptation profile membership. Caseworker reported maltreatment severity was a significant predictor of profile membership overall, but the only difference approaching significance between two groups actually showed slightly higher rates of reported maltreatment severity for the high overall adaptation group compared to the low overall adaptation group with poor behavior, but this difference was only marginally significant.

It is important to keep in mind that all four profiles were reported as having experienced mild to moderate maltreatment on average. This lack of results regarding child welfare variables, while not consistent with our hypotheses, could indicate that these subjective and limited measures of maltreatment type, severity, and substantiation are not detecting meaningful variation in youth experience or that they do not adequately 
measure the experience of children that have been maltreated. It is also possible that all youth in the child welfare service involved population have passed a threshold of risk and that these additional factors related to the experience of maltreatment do not explain additional meaningful variance in outcomes such as school adaptation. It may be the case that maltreatment experiences do not meaningful shape the school adaptation of youth, as this is a domain of functioning separate from the experiences at home. This separate environment provides an alternative setting in which children can thrive, regardless of their home lives. Perhaps the impact of child welfare indicators of maltreatment on school adaptation involves other pathways that are not as direct as the pathways hypothesized here. Overall, child welfare indicators were not critical determinants of school adaptation profiles in the present study.

\section{Aim 3: Examining the Role of School Adaptation in Buffering the Effects of Child Welfare Indicators of Maltreatment on Mental Health Outcomes.}

The goal of Aim 3 was to examine potential relationships between school adaptation profiles, child welfare indicators of maltreatment and mental health outcomes. This was accomplished using hierarchical linear regression to predict mental health outcomes after three years by maltreatment severity, school adaptation profiles, and relevant controls. A secondary goal of Aim 3 was to evaluate possible interactions of maltreatment severity and school adaptation. Race/ethnicity, substantiation of maltreatment, and alleged type of maltreatment experienced did not significantly predict mental health outcomes. As expected, mental health symptomology at Wave 1 significantly predicted later mental health symptomology. Consistent with our 
hypotheses, higher ratings of maltreatment severity predicted higher ratings of mental health problems at Wave 4. School adaptation profile membership significantly predicted later mental health problems in a mostly intuitive manner, with one unexpected finding. Not surprisingly, the high overall adaptation group experienced the lowest levels of mental health symptomology at Wave 4, and the low overall adaptation with poor behavior group experienced the greatest mental health symptomology at Wave 4 .

Also somewhat unexpectedly, the low overall adaptation with good behavior and low emotional/cognitive engagement group had the second lowest ratings of mental health symptomology at Wave 4, and the moderate overall adaptation with somewhat poor behavior group had the second highest. It is important to note that follow up analyses revealed that differences in mental health functioning between these two groups did not reach statistical significance, but this unexpected finding is still worth exploring. At first glance, this finding may seem counterintuitive as the moderate overall adaptation with somewhat poor behavior group seemed to be functioning better overall than the low overall adaptation with good behavior and low emotional/cognitive engagement group and would therefore be expected to have better mental health outcomes. It is important to consider the potential sources of these discrepancies. It may be that these ratings stem from the differences in areas of school adaptation difficulty and how these areas differentially impact caregiver ratings of mental health. Both the low overall adaptation with poor behavior group and the moderate overall adaptation with somewhat poor behavior group exhibited greater behavioral problems than the other two groups, potentially causing distress to caregivers resulting in higher ratings of mental health 
symptomology. While the low overall adaptation with good behavior and low emotional/cognitive engagement group appears to be worse off overall, it may be the case that these youth are internalizing their difficulties more, causing less distress for caregivers, and therefore going unrecognized as experiencing mental health difficulties. It may also be that behavioral difficulties at school are contributing to other areas not considered in these analyses, such as impaired relationships with parents, or poorer selfconcept, which negatively impact youth mental health functioning. While there is theoretical overlap between behavioral difficulties and mental health functioning, it is unlikely that these constructs were conflated in the current study as we controlled for previous mental health functioning and correlations between behavior indicators related to school adaptation and mental health functioning ranged from weak to moderate (all below 0.4 ), demonstrating that they reflect separate constructs.

Lastly, we hypothesized that school adaptation would buffer the impact of maltreatment severity on mental health functioning long-term. This study failed to find significant interactions of profile membership and caseworker reported severity of maltreatment on youth mental health functioning. There are several possible explanations for this unexpected finding. First, it may be the case that examining outcomes three years later made it impossible to detect buffering effects, as mental health had improved in the sample overall. Perhaps moderation effects would have been detectable while examining more proximal mental health outcomes. Additionally, the lack of significant interactions may be attributable to the fact that this sample did not include a non-child welfare system involved control group and that most of the sample, even those rated as experiencing no 
maltreatment, had passed an unknown threshold of risk simply by being involved with child welfare services. We expect that, with a narrower window of time and while including children and adolescents who most accurately represent the "no maltreatment" end of the spectrum (those that have no involvement with child welfare services), buffering effects of school adaptation on maltreatment severity may be found that were not in the present study.

In summary, the current study demonstrated a more sophisticated and personcentered way of understanding the nebulous construct of school adaptation than previously utilized. It also highlighted the importance of this nuanced understanding with regard to the long-term mental health of youth involved with child welfare services. We found support for four profiles of school adaptation among youth involved with the child welfare system, which were more complicated than simply high, low, and in-between. Profiles consisted of a high overall adaptation group, low overall adaptation group, and two more nuanced groups including a moderate overall adaptation with poor behavior group, and a low overall adaptation with especially poor emotional/cognitive engagement, but strong behavioral functioning. These profiles were related to demographic variables such as age and gender in the expected directions, but surprisingly, we did not find evidence of experiences related to child welfare involvement, including type of abuse investigated and substantiation of maltreatment, determining profile membership. Lastly, we found that severity of maltreatment and school adaptation profile membership were important predictors of later mental health functioning, with more severe maltreatment and poorer behavioral functioning at school 
predicting worse mental health outcomes. We did not find support for interactions of school adaptation and maltreatment severity in predicting youth mental health.

\section{Strengths, Limitations, and Future Directions}

The current study benefited from a number of strengths. First, this study utilized a large, longitudinal, and nationally representative sample of children who were involved with child welfare services regarding alleged maltreatment. This study also incorporated reports from youth, their caregivers, child welfare agency caseworkers, and teachers. It is also one of the first studies to examine profiles of school adaptation in this specific population. We are not aware of any other study examining school adaptation or engagement among child welfare service involved youth that simultaneously had this large of a sample, data from this many informants per youth, over a dozen indicators of school adaptation, and outcome data several years later.

Despite these notable strengths, this study also had several important limitations. First, there are several possible areas of concern regarding which respondents reported on specific constructs. This study relied on caregiver reports to measure youth mental health functioning. This is less than ideal, considering that some of these caregivers were foster parents who may have not known the children very long, and some of these caregivers were alleged perpetrators of abuse and neglect. It is possible that some of these caregivers were not able to provide the most accurate data on behavioral and emotional symptoms, such as potentially missing internalizing problems in the low overall adaptation with good behavior and low emotional/cognitive engagement group as noted above. Despite this potential, it was decided to utilize caregiver report of mental health functioning, 
given that self-report data was not available for children under 11 years of age, and there was substantially less mental health data available from teacher reports. Caregiver report data on mental health was also favored over teacher report because we wanted to understand the impact of school adaptation on mental health outside the school context. Conversely, youth report, including children as young as 4 years old, was utilized for 10 of the 14 indicators of school adaptation. While data collected from such young children may not be ideal, some indicators of school adaptation, including student-teacher relationships, feelings about school, and interest in classes, were only available from student reports. This limitation is not considered to be a major hindrance, as we were interested in understanding these aspects of school adaptation from the youth's perspective. Other components of school adaptation, such as behavioral challenges in school, necessitate report outside of the youth's perspective as they may not report accurately or honestly on their own behavior. We were able to incorporate reports on youth behavior from both students and teachers in these analyses, which were related. Future studies would benefit from incorporating measures and respondents that were not available in the current work, including teacher reports of student-teacher relationship quality and peer reports of youth social status in school.

Second, several of the measures utilized in this study do not have well-established psychometric properties. For example, the teacher report on youth behavioral difficulties at school is a limited series of two questions that ask teachers if the student's parents have been contacted regarding behavioral problems at school and if this has happened once or more than once. This measure of behavioral difficulties does not have established norms 
or psychometric properties and does not provide information about the nature of behavioral difficulties or specifics about the frequency of these problems. Additionally, the caseworker report on the Maltreatment Classification Scale (Manly, Cicchetti, \& Barnett, 1994), while a well-established measure, was adapted for the current study to include only a few items to assess the maltreatment experiences of youth. Perhaps reliance on a global measure of maltreatment severity influenced the lack of findings regarding interactions of maltreatment severity and school adaptation profile. The school engagement questions from the Drug-Free Schools and Communities Act Survey (Dowd et al., 2004) has limited information available regarding psychometric properties and factor structure. While the brief nature of many of these measures was appropriate given the range of topics covered in the NSCAW interviews, future work focused on school adaptation specifically would benefit from more comprehensive and well-validated measures of the many identified components of school adaptation.

Lastly, it should be mentioned that the NSCAW I data set is no longer in its youth, having started data collection in 1999. While many of the constructs examined in this study are as relevant today as they were nearly 20 years ago, it is important to note that there have been significant shifts in U.S. schools and education that may impact how youth interface with school. For example, the past two decades have witnessed the rise of standards-based education and assessment, the creation and implementation of the Common Core State Standards Initiative, and the increasing media attention on school shooting events since the Columbine High School massacre in 1999. It is impossible to know at this point how these changes in U.S. schools impact the dimensions and relative 
importance of school adaptation components. While the NSCAW data set continues to provide a wealth of information from which to draw knowledge, generalizations to the present day should be made with caution. Findings in this study should undergo replication with other, more current, samples.

The findings and limitations of the current study point the way towards a range of directions for future research. As mentioned above, future studies should incorporate multiple respondents on multiple indicators of school adaptation, utilize comprehensive and psychometrically sound measures, and replicate findings with other samples. Additionally, future studies should compare profiles of school adaptation among youth involved with child welfare services to those in the general population in order to understand how these profiles are similar or discrepant. Given the high rates of school instability among at-risk youth, it would also be important to explore how school instability impacts school adaptation with this nuanced and comprehensive view. Subsequent work may explore if school adaptation profiles predict other important outcomes, such as cognitive functioning, educational attainment, employment, or life satisfaction. Additionally, while this study was focused on school adaptation at the individual level, the gained understanding of school adaptation profiles and their impact on youth mental health may inform intervention at individual, classroom, and school levels in the future.

Clearly, schools are important in the lives of youth involved with the child welfare system, and success in this context can lead to better mental health outcomes. Successful school adaptation is not made or broken solely by experiences of adversity. It 
is important to note that successful school adaptation is also not as simple as performing well on standardized achievement tests. The findings of this study demonstrate the significant role of other aspects of school adaptation, including emotional, relational, cognitive, and behavioral connection to school.

The current studies highlighted the importance of behavioral functioning with regard to overall school adaptation, but behavioral health is generally regarded as a low priority compared to test scores and other more traditional indicators of success at school. In a special issue of interventions targeting student motivation and engagement, Wigfield and Wentzel (2007) raise the concern that too many school-based programs in the years following the No Child Left Behind (2003) legislation focused on the cognitive skills and academic performance of students, without due attention to the motivation and engagement of students. They discuss practices and interventions that are focused on aspects of youth adaptation at school, including motivation, positive social-emotional climates in schools, and social skills, that not only lead to social, emotional, and behavioral benefits, but also contribute to increased academic performance. Our findings support a broad conceptualization of school adaptation and potentially support corresponding interventions that go beyond academics and schoolwork to bolster the behavioral, social, and emotional components of school adaptation.

The last several decades have seen a rise in evidence-based interventions that target numerous aspects of school adaptation (Rathvon, 2008). Some promising interventions that move beyond academic intervention include programs that target student social interactions (e.g., Positive Peer Reporting; Morrison, \& Jones, 2007), self- 
monitoring of behavior (e.g., Three Steps to Self-Managed Behavior; Rathvon, 2008), and even interventions focused on improving aspects of the school environment outside the classroom, such as the playground (e.g., Loop the Loop: A Schoolwide Intervention to Reduce Problem Behavior on the Playground; Rathvon, 2008). These innovative programs address aspects of school adaptation that are often excluded from conceptualizations of school success but nonetheless play a role in youth school adaptation and mental health. Future research should endeavor to identify the ideal leverage points for improving school adaptation overall, then apply evidence-based interventions strategically to improve not only the academic competence of youth, but their overall experience and connection to school, and therefore impact distal and crucial outcomes.

\section{Conclusion}

School adaptation is an integral and important resilience factor for at-risk youth, such as those involved with the child welfare system due to alleged maltreatment. It is also a multifaceted and nuanced construct. This study was the first one known to these authors to explore the potential profiles of school adaptation among child welfare system involved youth, how these profiles are related to maltreatment experiences, and their impact on later mental health functioning. Support for our hypotheses was mixed. Results revealed four profiles of school adaptation which varied on a range of indicators including behavioral, emotional, and cognitive engagement, academic performance, relationships at school, and attendance. Variables related to maltreatment experience were not revealed to be critical determinants of school adaptation profile. Poorer school 
adaptation, especially poorer behavioral functioning, predicted worse mental health outcomes. The findings of this study support continued work to foster the development of the whole child, including academic, social, emotional, and behavioral competencies, as these are all aspects of a child's success in school and impact well-being beyond the classroom. 


\section{REFERENCES}

Achenbach, T. M., \& Rescorla, L. (2001). ASEBA School-Age Forms \& Profiles. Burlington: ASEBA.

Akaike, H. (1987). Factor analysis and AIC. Psychometrika, 52, 317-332.

Alexander, K. L., Entwisle, D. R., \& Dauber, S. L. (1993). First-grade classroom behavior: Its short-and long-term consequences for school performance. Child Development, 64(3), 801-814.

Appleton, J. J., Christenson, S. L., \& Furlong, M. J. (2008). Student engagement with school: Critical conceptual and methodological issues of the construct. Psychology in the Schools, 45(5), 369-386.

Archambault, I., Janosz, M., Fallu, J. S., \& Pagani, L. S. (2009). Student engagement and its relationship with early high school dropout. Journal of Adolescence, 32(3), $651-670$

Baker, J. A., Grant, S., \& Morlock, L. (2008). The teacher-student relationship as a developmental context for children with internalizing or externalizing behavior problems. School Psychology Quarterly, 23(1), 3.

Barnett, D., Vondra, J. I., \& Shonk, S. M. (1996). Self-perceptions, motivation, and school functioning of low-income maltreated and comparison children. Child Abuse \& Neglect, 20(5), 397-410.

Bell, M., Bayliss, D., Glauert, R., \& Ohan, J. (2018). Factors predicting out-of-school suspensions for young children. International Journal of Population Data Science, 3(4). 
Benard, B. (1995). Fostering resilience in children. ERIC Digest, ED386327. ERIC Clearinghouse on Elementary and Early Childhood Education, Urbana IL.

Benes, K. M. (1995). Review of the social skills rating system. The Twelfth Mental Measurements Yearbook, 965-967.

Bender, K. (2012). The mediating effect of school engagement in the relationship between youth maltreatment and juvenile delinquency. Children \& Schools, 34(1), 37-48.

Benedini, K. M., Fagan, A. A., \& Gibson, C. L. (2016). The cycle of victimization: The relationship between childhood maltreatment and adolescent peer victimization. Child Abuse \& Neglect, 59, 111-121.

Bethell, C. D., Newacheck, P., Hawes, E., \& Halfon, N. (2014). Adverse childhood experiences: assessing the impact on health and school engagement and the mitigating role of resilience. Health Affairs, 33(12), 2106-2115.

Bond, L., Butler, H., Thomas, L., Carlin, J., Glover, S., Bowes, G., \& Patton, G. (2007). Social and school connectedness in early secondary school as predictors of late teenage substance use, mental health, and academic outcomes. Journal of Adolescent Health, 40(4), 357-e9.

Bowlby, J. (1969). Attachment and Loss: Volume One: Attachment. New York: Basic Books.

Bulotsky-Shearer, R. J., \& Fantuzzo, J. W. (2011). Preschool behavior problems in classroom learning situations and literacy outcomes in kindergarten and first grade. Early Childhood Research Quarterly, 26(1), 61-73. 
Burns, B. J., Phillips, S. D., Wagner, H. R., Barth, R. P., Kolko, D. J., Campbell, Y., \& Landsverk, J. (2004). Mental health need and access to mental health services by youths involved with child welfare: A national survey. Journal of the American Academy of Child \& Adolescent Psychiatry, 43(8), 960-970.

Cassidy, J. \& Shaver, P. R. (1999). Handbook of attachment: Theory, research, and clinical applications. New York: Guilford.

Chase, P. A., Hilliard, L. J., Geldhof, G. J., Warren, D. J., \& Lerner, R. M. (2014). Academic achievement in the high school years: The changing role of school engagement. Journal of Youth and Adolescence, 43(6), 884-896.

Coohey, C., Renner, L. M., Hua, L., Zhang, Y. J., \& Whitney, S. D. (2011). Academic achievement despite child maltreatment: A longitudinal study. Child Abuse \& Neglect, 35(9), 688-699.

Cook, A., Spinazzola, J., Ford, J., Lanktree, C., Blaustein, M., Cloitre, M., \& Van der Kolk, B. (2005). Complex trauma. Psychiatric Annals, 35(5), 390-398.

Daignault, I. V., \& Hébert, M. (2008). Short-term correlates of child sexual abuse: an exploratory study predicting girls' academic, cognitive, and social functioning 1 year later. Journal of Child \& Adolescent Trauma, 1(4), 301-316.

Demaray, M. K., \& Malecki, C. K. (2002). The relationship between perceived social support and maladjustment for students at risk. Psychology in the Schools, 39(3), 305-316.

DeSocio, J., \& Hootman, J. (2004). Children's mental health and school success. The Journal of School Nursing, 20(4), 189-196. 
Diseth, Å., Danielsen, A. G., \& Samdal, O. (2012). A path analysis of basic need support, self-efficacy, achievement goals, life satisfaction and academic achievement level among secondary school students. Educational Psychology, 32(3), 335-354.

Dowd, K., Kinsey, S., Wheeless, S., Thissen, R., Richardson, J., Suresh, R., ... \& Smith, K. Q. (2004). National Survey of Child and Adolescent Well-Being (NSCAW), Combined Waves 1-4, Data File User's Manual, Restricted Release Version. Research Triangle Institute, University of North Carolina at Chapel Hill, and Caliber Associates. University of California at Berkeley.

Dryden, J., Johnson, B., Howard, S., \& McGuire, A. (1998, April). Resiliency: A comparison of construct definitions arising from conversations with 9 year old 12 year old children and their teachers. Paper presented at the Annual Meeting of the American Educational Research Association, San Diego, CA.

Durán-Narucki, V. (2008). School building condition, school attendance, and academic achievement in New York City public schools: A mediation model. Journal of Environmental Psychology, 28(3), 278-286.

Eckenrode, J., Laird, M., \& Doris, J. (1993). School performance and disciplinary problemsamong abused and neglected children. Developmental Psychology, 29(1), 53.

Fantuzzo, J. W., Perlman, S. M., \& Dobbins, E. K. (2011). Types and timing of child maltreatment and early school success: A population-based investigation. Children and Youth Services Review, 33(8), 1404-1411. 
Finn, J. D. (1993). School Engagement \& Students at Risk. Report for the National Center for Education Statistics (ED), Washington, DC.

Fredricks, J. A., Blumenfeld, P. C., \& Paris, A. H. (2004). School engagement: Potential of the concept, state of the evidence. Review of Educational Research, 74(1), 59109.

Furrer, C., \& Skinner, E. (2003). Sense of relatedness as a factor in children's academic engagement and performance. Journal of Educational Psychology, 95(1), 148.

Gamache Martin, C., Cromer, L. D., \& Freyd, J. J. (2010). Teachers' beliefs about maltreatment effects on student learning and classroom behavior. Journal of Child \& Adolescent Trauma, 3(4), 245-254.

Gilbert, R., Widom, C. S., Browne, K., Fergusson, D., Webb, E., \& Janson, S. (2009). Burden and consequences of child maltreatment in high-income countries. The Lancet, 373(9657), 68-81.

Gilligan, R. (2000). Adversity, resilience and young people: The protective value of positive school and spare time experiences. Children \& Society, 14(1), 37-47.

Greeson, J. K., Briggs, E. C., Kisiel, C. L., Layne, C. M., Ake III, G. S., Ko, S. J., ... \& Fairbank, J. A. (2011). Complex trauma and mental health in children and adolescents placed in foster care: Findings from the National Child Traumatic Stress Network. Child Welfare, 90(6), 91.

Gresham, F. M., \& Elliott, S. N. (1990). Social skills rating system (SSRS). American Guidance Service. 
Hagborg, J. M., Berglund, K., \& Fahlke, C. (2018). Evidence for a relationship between child maltreatment and absenteeism among high-school students in Sweden. Child Abuse \& Neglect, 75, 41-49.

Hamre, B.K., \& Pianta, R. C. (2001). Early teacher-child relationships and the trajectory of children's school outcomes through eighth grade. Child Development, 72(2), 625-638.

Howes, C., Rodning, C., Galluzzo, D. C., \& Myers, L. (1988). Attachment and child care: Relationships with mother and caregiver. Early Childhood Research Quarterly, 3(4), 403-416.

IBM Corp. Released 2013. IBM SPSS Statistics for Windows, Version 22.0. Armonk, NY: IBM Corp.

Janosz, M., Archambault, I., Morizot, J., \& Pagani, L. S. (2008). School engagement trajectories and their differential predictive relations to dropout. Journal of Social Issues, 64(1), 21-40.

Jimerson, S. R., Campos, E., \& Greif, J. L. (2003). Toward an understanding of definitions and measures of school engagement and related terms. The California School Psychologist, 8(1), 7-27.

Johnson, M. K., Crosnoe, R., \& Elder Jr, G. H. (2001). Students' attachment and academic engagement: The role of race and ethnicity. Sociology of Education, 74(4), 318-340. 
Jonson-Reid, M., Drake, B., Kim, J., Porterfield, S., \& Han, L. (2004). A prospective analysis of the relationship between reported child maltreatment and special education eligibility among poor children. Child Maltreatment, 9(4), 382-394.

Kaplan, S. J., Pelcovitz, D., \& Labruna, V. (1999). Child and adolescent abuse and neglect research: A review of the past 10 years. Part I: Physical and emotional abuse and neglect. Journal of the American Academy of Child \& Adolescent Psychiatry, 38(10), 1214-1222.

Kearney, C. A. (2008). School absenteeism and school refusal behavior in youth: A contemporary review. Clinical Psychology Review, 28(3), 451-471.

Kendall-Tackett, K. A., \& Eckenrode, J. (1996). The effects of neglect on academic achievement and disciplinary problems: A developmental perspective. Child Abuse \& Neglect, 20(3), 161-169.

Kerr, M. A., Black, M. M., \& Krishnakumar, A. (2000). Failure-to-thrive, maltreatment and the behavior and development of 6-year-old children from low-income, urban families: A cumulative risk model. Child Abuse \& Neglect, 24(5), 587-598.

Kessler, R. C., McLaughlin, K. A., Green, J. G., Gruber, M. J., Sampson, N. A., Zaslavsky, A. M., ... \& Williams, D. R. (2010). Childhood adversities and adult psychopathology in the WHO World Mental Health Surveys. The British Journal of Psychiatry, 197(5), 378-385.

Kiesel, L. R., Piescher, K. N., \& Edleson, J. L. (2016). The relationship between child maltreatment, intimate partner violence exposure, and academic performance. Journal of Public Child Welfare, 10(4), 434-456. 
Konold, T., Cornell, D., Shukla, K., \& Huang, F. (2017). Racial/ethnic differences in perceptions of school climate and its association with student engagement and peer aggression. Journal of Youth and Adolescence, 46(6), 1289-1303.

Košir, K., \& Tement, S. (2014). Teacher-student relationship and academic achievement: A cross-lagged longitudinal study on three different age groups. European Journal of Psychology of Education, 29(3), 409-428.

Kremer, K. P., Flower, A., Huang, J., \& Vaughn, M. G. (2016). Behavior problems and children's academic achievement: A test of growth-curve models with gender and racial differences. Children and Youth Services Review, 67, 95-104.

Laditka, J. N., \& Laditka, S. B. (2016). Associations of educational attainment with disability and life expectancy by race and gender in the United States: A longitudinal analysis of the Panel Study of Income Dynamics. Journal of Aging and Health, 28(8), 1403-1425.

Leiter, J. (2007). School performance trajectories after the advent of reported maltreatment. Children and Youth Services Review, 29(3), 363-382.

Leiter, J., \& Johnsen, M. C. (1994). Child maltreatment and school performance. American Journal of Education, 102(2), 154-189.

Leonard, S. S., \& Gudiño, O. G. (2016). Academic and mental health outcomes of youth placed in out-of-home care: The role of school stability and engagement. In Child \& Youth Care Forum (Vol. 45, No. 6, pp. 807-827). Springer US. 
Leonard, S., Stiles, A., \& Gudiño, O.G. (2016). School engagement of youth investigated by Child Welfare Services: Associations with academic achievement and mental health. School Mental Health, 8(3), 386-398.

Lereya, S. T., Copeland, W. E., Costello, E. J., \& Wolke, D. (2015). Adult mental health consequences of peer bullying and maltreatment in childhood: two cohorts in two countries. The Lancet Psychiatry, 2(6), 524-531.

Libbey, H. P. (2004). Measuring student relationships to school: Attachment, bonding, connectedness, and engagement. Journal of School Health, 74(7), 274-283.

Lo, Y., Mendell, N. R., \& Rubin, D. B. (2001). Testing the number of components in a normal mixture. Biometrika, 88, 767-778.

Luthar, S. S., Cicchetti, D., \& Becker, B. (2000). The construct of resilience: A critical evaluation and guidelines for future work. Child Development, 71(3), 543-562.

Luthar, S. S. (2015). Resilience in development: A synthesis of research across five decades. Developmental Psychopathology: Volume Three: Risk, Disorder, and Adaptation, 739-795.

Lynch, M., \& Cicchetti, D. (1992). Maltreated children's reports of relatedness to their teachers. New Directions for Child and Adolescent Development, 1992(57), 81107.

Maguire, S. A., Williams, B., Naughton, A. M., Cowley, L. E., Tempest, V., Mann, M. K., ... \& Kemp, A. M. (2015). A systematic review of the emotional, behavioural and cognitive features exhibited by school-aged children experiencing neglect or emotional abuse. Child Care, Health and Development, 41(5), 641-653. 
Manly, J. T., Cicchetti, D., \& Barnett, D. (1994). The impact of subtype, frequency, chronicity, and severity of child maltreatment on social competence and behavior problems. Development and Psychopathology, 6(01), 121-143.

Masten, A. S., \& Wright, M. O. (2010). Resilience over the lifespan: Developmental perspectives on resistance, recovery, and transformation (pp. 213-237). New York, NY: Guilford.

Masten, A. S. (2014). Global perspectives on resilience in children and youth. Child Development, 85(1), 6-20.

Maughan, A., \& Cicchetti, D. (2002). Impact of child maltreatment and interadult violence on children's emotion regulation abilities and socioemotional adjustment. Child Development, 73(5), 1525-1542.

McGuire, A., \& Jackson, Y. (2018). Dimensions of maltreatment and academic outcomes for youth in foster care. Child Abuse \& Neglect, 84, 82-94.

Morrissey, T. W., Hutchison, L., \& Winsler, A. (2014). Family income, school attendance, and academic achievement in elementary school. Developmental Psychology, 50(3), 741.

Morrison, G. M., \& Allen, M. R. (2007). Promoting student resilience in school contexts. Theory into Practice, 46(2), 162-169.

Morrison, J. Q., \& Jones, K. M. (2007). The effects of positive peer reporting as a classwide positive behavior support. Journal of Behavioral Education, 16(2), 111-124.

Moylan, C. A., Herrenkohl, T. I., Sousa, C., Tajima, E. A., Herrenkohl, R. C., \& Russo, M. J. (2010). The effects of child abuse and exposure to domestic violence on 
adolescent internalizing and externalizing behavior problems. Journal of Family Violence, 25(1), 53-63.

Murray Nettles, S., Mucherah, W., \& Jones, D. S. (2000). Understanding resilience: The role of social resources. Journal of Education for Students Placed at Risk, 5(1-2), $47-60$.

Muthén, L. K., \& Muthén, B. O. (2010). Mplus software (Version 6). Los Angeles, CA: Muthén \& Muthén.

No Child Left Behind (NCLB) Act of 2001, 20 U.S.C.A. $§ 6301$ et seq. (West 2003).

Nelson, J. R., Benner, G. J., Lane, K., \& Smith, B. W. (2004). Academic achievement of K-12 students with emotional and behavioral disorders. Exceptional Children, 71(1), 59-73.

Oberski, D. (2016). Mixture models: Latent profile and latent class analysis. In Modern Statistical Methods for HCI (pp. 275-287). Springer International Publishing.

Oh, I., \& Song, J. (2018). Mediating effect of emotional/behavioral problems and academic competence between parental abuse/neglect and school adjustment. Child Abuse \& Neglect, 86, 393-402.

Patterson, G. R., DeBaryshe, B. D., \& Ramsey, E. (2017). A developmental perspective on antisocial behavior. In Developmental and Life-course Criminological Theories (pp. 29-35). Routledge.

Pears, K. C., Kim, H. K., Fisher, P. A., \& Yoerger, K. (2013). Early school engagement and late elementary outcomes for maltreated children in foster care. Developmental Psychology, 49(12), 2201. 
Petrucci, C. J. (2009). A primer for social worker researchers on how to conduct a multinomial logistic regression. Journal of Social Service Research, 35(2), 193205.

Price, J. M., \& Glad, K. (2003). Hostile attributional tendencies in maltreated children. Journal of Abnormal Child Psychology, 31(3), 329-343.

Ratner, H. H., Chiodo, L., Covington, C., Sokol, R. J., Ager, J., \& Delaney-Black, V. (2006). Violence exposure, IQ, academic performance, and children's perception of safety: Evidence of protective effects. Merrill-Palmer Quarterly, 52(2), 264287.

Rathvon, N. (2008). Effective school interventions: Evidence-based strategies for improving student outcomes. Guilford Press.

Romano, E., Babchishin, L., Marquis, R., \& Fréchette, S. (2015). Childhood maltreatment and educational outcomes. Trauma, Violence, \& Abuse, 16(4), 418437.

Roby, D. E. (2004). Research on school attendance and student achievement: A study of Ohio schools. Educational Research Quarterly, 28(1), 3.

Roorda, D. L., Jak, S., Zee, M., Oort, F. J., \& Koomen, H. M. (2017). Affective teacherstudent relationships and students' engagement and achievement: A meta-analytic update and test of the mediating role of engagement. School Psychology Review, 46(3), 239-261.

Roorda, D. L., Koomen, H. M., Split, J. L. \& Oort, F. J. (2011). The influence of affective teacher-student relationships on students' school engagement and 
achievement: A meta-analytic approach. Review of Educational Research, 81(4), 493-529.

Ryan, J. P., Jacob, B. A., Gross, M., Perron, B. E., Moore, A., \& Ferguson, S. (2018). Early exposure to child maltreatment and academic outcomes. Child Maltreatment, 23(4), 365-375.

Schwartz, G. (1978). Estimating the dimension of a model. The Annals of Statistics, 6, $461-464$.

Sclove, L. S. (1987). Application of model-selection criteria to some problems in multivariate analysis. Psychometrika, 52, 333-343.

Shochet, I. M., Dadds, M. R., Ham, D., \& Montague, R. (2006). School connectedness is an underemphasized parameter in adolescent mental health: Results of a community prediction study. Journal of Clinical Child and Adolescent Psychology, 35(2), 170-179.

Shonk, S. M., \& Cicchetti, D. (2001). Maltreatment, competency deficits, and risk for academic and behavioral maladjustment. Developmental Psychology, 37(1), 3.

Silver, R. B., Measelle, J. R., Armstrong, J. M., \& Essex, M. J. (2005). Trajectories of classroom externalizing behavior: Contributions of child characteristics, family characteristics, and the teacher-child relationship during the school transition. Journal of School Psychology, 43(1), 39-60.

Sirin, S. R. (2005). Socioeconomic status and academic achievement: A meta-analytic review of research. Review of Educational Research, 75(3), 417-453. 
Slade, E. P., \& Wissow, L. S. (2007). The influence of childhood maltreatment on adolescents' academic performance. Economics of Education Review, 26(5), 604614.

Staudt, M. M. (2001). Psychopathology, peer relations, and school functioning of maltreated children: A literature review. Children \& Schools, 23(2), 85-100.

Stiles, A. A., \& Gudiño, O. G. (2018). Examining bidirectional associations between school engagement and mental health for youth in child welfare. School Mental Health, 10(4), 372-385.

Thorvaldsen, M. (2005). Review of Teacher Report Form. Taylor, N., Igelman., and Kulkarni., M. (Eds.), National Child Traumatic Stress Network Measure Review Database. Retrieved March 27, 2017 from http://www.nctsnet.org/nctsn_assets/pdfs/measure/TRF

Tyler, K. A., Johnson, K. A., \& Brownridge, D. A. (2008). A longitudinal study of the effects of child maltreatment on later outcomes among high-risk adolescents. Journal of Youth and Adolescence, 37(5), 506-521.

Upadyaya, K., \& Salmela-Aro, K. (2013). Development of school engagement in association with academic success and well-being in varying social contexts: A review of empirical research. European Psychologist, 18(2), 136.

US Department of Health and Human Services. (2013). Child maltreatment 2012.

Veltman, M. W., \& Browne, K. D. (2001). Three decades of child maltreatment research: Implications for the School Years. Trauma, Violence, \& Abuse, 2(3), 215-239. 
Vondra, J., Barnett, D., \& Cicchetti, D. (1989). Perceived and actual competence among maltreated and comparison school children. Development and Psychopathology, $1(3), 237-255$.

Wang, M. T., \& Fredricks, J. A. (2014). The reciprocal links between school engagement, youth problem behaviors, and school dropout during adolescence. Child Development, 85(2), 722-737.

Wang, M. T., \& Peck, S. C. (2013). Adolescent educational success and mental health vary across school engagement profiles. Developmental Psychology, 49(7), 1266.

Wentzel, K. R. (1993). Does being good make the grade? Social behavior and academic competence in middle school. Journal of Educational Psychology, 85(2), 357.

Wigfield, A., \& Wentzel, K. R. (2007). Introduction to motivation at school: Interventions that work. Educational Psychologist, 42(4), 191-196.

Wodarski, J. S., Kurtz, P. D., Gaudin Jr, J. M., \& Howing, P. T. (1990). Maltreatment and the school-age child: Major academic, socioemotional, and adaptive outcomes. Social Work, 35(6), 506-513.

Woodcock, R. W., McGrew, K. S., \& Werder, J. K. (1994). Woodcock-McGrew-Werder mini-battery of achievement. Chicago, IL: Riverside Publishing. 


\section{APPENDIX A: TABLES}

Table 1

Descriptive Statistics for All Variables

\begin{tabular}{lcccccc}
\hline Variable & $\mathrm{N}$ & $\%$ & Min. & Max. & M & SE \\
\hline $\begin{array}{l}\text { Demographics } \\
\text { Age }\end{array}$ & 2667 & - & 4 & 16 & 9.96 & .06 \\
$\quad \begin{array}{l}\text { Gender } N=2,668 \\
\quad \text { Female }\end{array}$ & 1409 & 52.8 & - & - & - & - \\
$\quad$ Male & 1259 & 47.2 & - & - & - & - \\
$\quad$ Race $N=2,456$ & 1218 & 45.7 & - & - & - & - \\
$\quad$ White & 791 & 29.6 & - & - & - & - \\
$\quad$ Black & 439 & 16.5 & - & - & - & - \\
$\quad$ Hispanic & 212 & 7.9 & - & - & - & - \\
$\quad$ Other & & & & & &
\end{tabular}

Child Welfare Variables

Alleged Type of Maltreatment $N=2,445$

$\begin{array}{lcc}\text { Physical } & 629 & 25.7 \\ \text { Sexual } & 439 & 18.0 \\ \text { Emotional } & 188 & 7.7 \\ \text { Neglect } & 1022 & 41.8 \\ \text { Other } & 167 & 6.8\end{array}$

Substantiation of Maltreatment $N=2,668$

$\begin{array}{lll}\text { Substantiated } & 1607 & 60.2 \\ \text { Other than Substantiated } & 1061 & 39.8\end{array}$

Severity of maltreatment $N=2,447$

None

Mild

Moderate

Severe

School Adaptation Indicators

$\mathrm{S}$ - Enjoy school

S - Hate school

S - Try your best on work

$\mathrm{S}$ - Find classes interesting

$S$ - Sent to office

$\mathrm{S}$ - Get along w/ teachers

S - Pay attention

$\mathrm{S}$ - Complete homework

$\mathrm{S}$ - Get along w/ other students

$\mathrm{S}$ - Woodcock-Johnson scores

$\mathrm{T}$ - Academic performance
592

710

761

387

24.2

29.0

31.1

15.7

$\begin{array}{llcccc}2429 & - & 1 & 4 & 2.96 & .02 \\ 2422 & - & 1 & 4 & 1.95 & .02 \\ 2420 & - & 1 & 4 & 3.41 & .02 \\ 2397 & - & 1 & 4 & 2.70 & .02 \\ 2416 & - & 1 & 4 & 1.47 & .02 \\ 2412 & - & 1 & 4 & 3.24 & .02 \\ 2414 & - & 1 & 4 & 3.21 & .02 \\ 2406 & - & 1 & 4 & 3.24 & .02 \\ 2410 & - & 1 & 4 & 3.09 & .02 \\ 2490 & - & 10.50 & 197.00 & 93.15 & .41 \\ 1210 & - & 1 & 5 & 2.48 & .03\end{array}$




\begin{tabular}{lrrrrrr} 
T - SSRS classroom behavior & 1258 & - & 0 & 20 & 12.40 & .14 \\
T - Contact parents re behavior & 1231 & - & 0 & 2 & .89 & .03 \\
T - Days absent & 920 & - & 0 & 153 & 10.51 & .46 \\
School Adaptation Profile Membership N & 2,668 & & & & \\
Profile 1 & 474 & 17.8 & - & - & - & - \\
Profile 2 & 610 & 22.9 & - & - & - & - \\
Profile 3 & 246 & 9.2 & - & - & - & - \\
Profile 4 & 1338 & 50.1 & - & - & - & \\
Wave 1 Mental Health T-Score & 2632 & - & 23 & 94 & 59.36 & .24 \\
Wave 4 Mental Health T-Score & 2203 & - & 23 & 94 & 57.32 & .27 \\
\hline Notes: $N$ ranges from 920 to 2,668, depending on available data. S indicates student rated \\
and completed variables. T indicates teacher rated variables.
\end{tabular}


Table 2

Constructs, Respondents, and Measures for All Variables

\begin{tabular}{|c|c|c|c|}
\hline Theme & Constructs & Respondent & Measures/Items \\
\hline Demographics & $\begin{array}{l}\text { Youth age, gender, } \\
\text { race/ethnicity }\end{array}$ & $\begin{array}{l}\text { Youth, } \\
\text { caregivers, } \\
\text { and } \\
\text { caseworkers }\end{array}$ & $\begin{array}{l}\text { NSCAW derived variables } \\
\text { utilizing reports from two or } \\
\text { more respondents. }\end{array}$ \\
\hline \multirow[t]{3}{*}{$\begin{array}{l}\text { Youth } \\
\text { Experience of } \\
\text { Maltreatment }\end{array}$} & $\begin{array}{l}\text { Alleged type of } \\
\text { maltreatment } \\
\text { leading to } \\
\text { investigation }\end{array}$ & Caseworkers & $\begin{array}{l}\text { Maltreatment Classification } \\
\text { Scale } \\
\text { Please look at Card } 8 \text { and tell me } \\
\text { the type or types of abuse or } \\
\text { neglect reported on [FILL } \\
\text { REPORT DATE]? } \\
\text { Of the types of abuse or neglect } \\
\text { that were reported, please look at } \\
\text { Card } 8 \text { and tell me the type that } \\
\text { you felt was the most serious. }\end{array}$ \\
\hline & $\begin{array}{l}\text { Substantiation of } \\
\text { Maltreatment }\end{array}$ & Caseworkers & $\begin{array}{l}\text { Maltreatment Classification } \\
\text { Scale } \\
\text { NSCAW derived variable } \\
\text { categorizing maltreatment as } \\
\text { substantiated or not. }\end{array}$ \\
\hline & $\begin{array}{l}\text { Severity of } \\
\text { maltreatment/Level } \\
\text { of harm to child }\end{array}$ & Caseworkers & $\begin{array}{l}\text { Maltreatment Classification } \\
\text { Scale } \\
\text { Regardless of the outcome of the } \\
\text { investigation, how would you } \\
\text { describe the level of harm to } \\
\text { [FILL CHILD]? Would you } \\
\text { say... }\end{array}$ \\
\hline $\begin{array}{l}\text { Youth mental } \\
\text { health }\end{array}$ & $\begin{array}{l}\text { Youth mental } \\
\text { health }\end{array}$ & Caregivers & $\begin{array}{l}\text { Total Problems scale T-score at } \\
\text { waves } 1 \text { and } 4\end{array}$ \\
\hline \multirow[t]{2}{*}{$\begin{array}{l}\text { Academic } \\
\text { Achievement }\end{array}$} & $\begin{array}{l}\text { Academic } \\
\text { Performance }\end{array}$ & Teachers & $\begin{array}{l}\text { Teacher Report Form } \\
\text { Average ranking across subjects } \\
\text { for: } \\
\text { What is the student's current } \\
\text { school performance? }\end{array}$ \\
\hline & $\begin{array}{l}\text { Academic } \\
\text { Achievement } \\
\text { (Standardized } \\
\text { performance) }\end{array}$ & Youth & $\begin{array}{l}\text { Woodcock-Johnson Mini Battery } \\
\text { of Achievement combined } \\
\text { standard score for math and } \\
\text { reading }\end{array}$ \\
\hline Attendance & Attendance & Teacher & $\begin{array}{l}\text { NSCAW derived question: } \\
\text { Since the beginning of the school } \\
\text { year, how many days in total has } \\
\text { this student been absent? }\end{array}$ \\
\hline
\end{tabular}




\begin{tabular}{|c|c|c|c|}
\hline \multirow[t]{2}{*}{ Relationships } & Peer Relationships & Youth & $\begin{array}{l}\text { School Engagement } \\
\text { Questionnaire Item } 11 \\
\text { 11. How often do you get } \\
\text { along with other students? }\end{array}$ \\
\hline & $\begin{array}{l}\text { Student-Teacher } \\
\text { Relationship }\end{array}$ & Youth & $\begin{array}{l}\text { School Engagement } \\
\text { Questionnaire Item } 8 \\
\text { 8. How often do you get } \\
\text { along with your teachers? }\end{array}$ \\
\hline $\begin{array}{l}\text { Emotional } \\
\text { Engagement }\end{array}$ & $\begin{array}{l}\text { Emotional } \\
\text { Engagement }\end{array}$ & Youth & $\begin{array}{l}\text { School Engagement } \\
\text { Questionnaire Items } 1 \text { and } 2 \\
\text { 1. How often do you enjoy } \\
\text { being in school? } \\
\text { 2. How often do you hate } \\
\text { being in school? }\end{array}$ \\
\hline $\begin{array}{l}\text { Cognitive } \\
\text { Engagement }\end{array}$ & $\begin{array}{l}\text { Cognitive } \\
\text { Engagement }\end{array}$ & Youth & $\begin{array}{l}\text { School Engagement } \\
\text { Questionnaire Item } 5 \\
\text { 5. How often do you find your } \\
\text { classes interesting? }\end{array}$ \\
\hline \multirow[t]{3}{*}{ Behavior } & $\begin{array}{l}\text { Behavioral } \\
\text { Engagement }\end{array}$ & Youth & $\begin{array}{l}\text { School Engagement } \\
\text { Questionnaire Items } 3,7,9 \text {, and } \\
\text { 10 } \\
\text { 3. How often do you try to } \\
\text { do your best work in } \\
\text { school? } \\
\text { 7. How often do you get sent } \\
\text { to the office, or have to stay } \\
\text { after school, because you } \\
\text { misbehaved? } \\
\text { 9. How often do you listen } \\
\text { carefully or pay attention in } \\
\text { school? } \\
\text { 10. How often do you get } \\
\text { your homework done? }\end{array}$ \\
\hline & $\begin{array}{l}\text { Classroom } \\
\text { Behavior }\end{array}$ & Teacher & $\begin{array}{l}\text { Social Skills Rating System - } \\
\text { Cooperation Scale standard score }\end{array}$ \\
\hline & Behavior Problems & Teacher & $\begin{array}{l}\text { Study derived questions } \\
\text { combined into 0-2 scale } \\
\text { 1. In this school year, has } \\
\text { the student had any } \\
\text { behavior or discipline } \\
\text { problems at this school } \\
\text { which resulted in the } \\
\text { student's parents being } \\
\text { sent a note or being asked }\end{array}$ \\
\hline
\end{tabular}




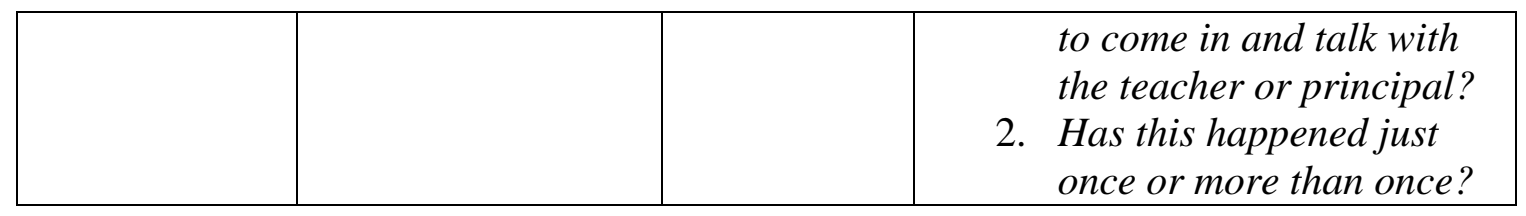


Table 3

Bivariate Correlations of School Adaptation Indicators

\begin{tabular}{|c|c|c|c|c|c|c|c|c|c|c|c|c|c|}
\hline Variable & 1 & 2 & 3 & 4 & 5 & 6 & 7 & 8 & 9 & 10 & 11 & 12 & 13 \\
\hline 1. S - Enjoy school & - & & & & & & & & & & & & \\
\hline 2. S - Hate school & $-.46 * *$ & - & & & & & & & & & & & \\
\hline $\begin{array}{l}\text { 3. } \mathrm{S}-\text { Try your } \\
\text { best on work }\end{array}$ & $.21 * *$ & $-.13 * *$ & - & & & & & & & & & & \\
\hline $\begin{array}{l}\text { 4. S - Find classes } \\
\text { interesting }\end{array}$ & $.30 * *$ & $-.21 * *$ & $.14 * *$ & - & & & & & & & & & \\
\hline 5. S - Sent to office & $-.14 * *$ & $.18 * *$ & $-.18 * *$ & $-.12 * *$ & - & & & & & & & & \\
\hline $\begin{array}{l}\text { 6. S - Get along w/ } \\
\text { teachers }\end{array}$ & $.32 * *$ & $-.23 * *$ & $.28 * *$ & $.27 * *$ & $-.28 * *$ & - & & & & & & & \\
\hline 7. S - Pay attention & $.25 * *$ & $-.17 * *$ & $.37 * *$ & $.22 * *$ & $-.27 * *$ & $.34 * *$ & - & & & & & & \\
\hline $\begin{array}{l}\text { 8. S-Complete } \\
\text { homework }\end{array}$ & $.24 * *$ & $-.15 * *$ & $.33 * *$ & $.19 * *$ & $-.23 * *$ & $.29 * *$ & $.34 * *$ & - & & & & & \\
\hline $\begin{array}{l}\text { 9. S - Get along w/ } \\
\text { other students }\end{array}$ & $.20 * *$ & $-.13 * *$ & $.19 * *$ & $.19 * *$ & $-.16 * *$ & $.28 * *$ & $.23 * *$ & $.20 * *$ & - & & & & \\
\hline $\begin{array}{l}\text { 10. } \mathrm{S}-\text { Woodcock } \\
\text { Johnson scores }\end{array}$ & .00 & -.04 & $.11 * *$ & .01 & $-.11 * *$ & $.11 * *$ & $.13 * *$ & $.13 * *$ & $.13 * *$ & - & & & \\
\hline $\begin{array}{l}\text { 11. } \mathrm{T}-\text { Academic } \\
\text { performance }\end{array}$ & $.11 * *$ & $-.13 * *$ & $.19 * *$ & .04 & $-.16 * *$ & $.17 * *$ & $.21 * *$ & $.25 * *$ & $.08 * *$ & $.52 * *$ & - & & \\
\hline $\begin{array}{l}\text { 12. T - SSRS } \\
\text { classroom } \\
\text { behavior }\end{array}$ & $.17 * *$ & $-.12 * *$ & $.18 * *$ & $.07 *$ & $-.26 * *$ & $.21 * *$ & $.19 * *$ & $.26 * *$ & $.15 * *$ & $.24 * *$ & $.51 * *$ & - & \\
\hline $\begin{array}{l}\text { 13. } \mathrm{T}-\text { Contact } \\
\text { parents } \\
\text { behavior }\end{array}$ & $-.16 * *$ & $.09 * *$ & $-.08 * *$ & $-.07 *$ & $.32 * *$ & $-.23 * *$ & $-.15 * *$ & $-.11 * *$ & $-.09 * *$ & $-.17 * *$ & $-.23 * *$ & $-.46 * *$ & - \\
\hline 14. $\mathrm{T}$ - Days absent & $-.16 * *$ & $.18 * *$ & $-.07 *$ & -.06 & $.09 *$ & $-.08 *$ & .01 & $-.07 *$ & -.03 & $-.08 *$ & $-.19 * *$ & $-.14 * *$ & $.17 * *$ \\
\hline
\end{tabular}

Notes: $N$ ranges from 795 to 2,490 , depending on available data. $\mathrm{S}$ indicates student rated and completed variables. T indicates teacher rated variables. $* *<0.01, *<0.05$ 
Table 4

Fit Indices and Entropies for Latent Profile Analysis Models

\begin{tabular}{lcccccccc}
\hline $\begin{array}{l}\text { Number of } \\
\text { Profiles }\end{array}$ & LogL & $\begin{array}{l}\text { Best LogL } \\
\text { replicated }\end{array}$ & $\begin{array}{c}\text { Number of } \\
\text { Parameters }\end{array}$ & AIC & BIC & SABIC & LMR-LRT (p) & Entropy \\
\hline 1 Profile & -39439.059 & Yes & 28 & 78934.119 & 79099.013 & 79010.048 & - & - \\
2 Profiles & -37769.407 & Yes & 43 & 75624.813 & 75878.044 & 75741.420 & $3311.323(0.0487)$ & 0.780 \\
3 Profiles & -37211.070 & Yes & 58 & 74538.140 & 74879.707 & 74695.424 & $1107.315(0.5720)$ & 0.699 \\
4 Profiles & -36100.066 & Yes & 73 & 72346.132 & 72776.036 & 72544.092 & $1396.246(0.6636)$ & 0.833 \\
5 Profiles & -35787.113 & No & 88 & 71750.226 & 72268.466 & 71988.863 & $430.039(0.5380)$ & 0.849 \\
6 Profiles & -35102.542 & No & 103 & 70411.085 & 71017.661 & 70690.398 & $1072.539(0.7119)$ & 0.838 \\
7 Profiles & -34836.727 & No & 118 & 69909.454 & 70604.366 & 70229.444 & $527.913(0.5921)$ & 0.796 \\
8 Profiles & -34383.188 & Yes & 133 & 69032.377 & 69815.625 & 69393.043 & $744.982(0.7128)$ & 0.795 \\
9 Profiles & -34259.974 & No & 148 & 68815.948 & 69687.533 & 69217.292 & $242.150(0.7717)$ & 0.789 \\
10 Profiles & -34321.939 & No & 163 & 68969.877 & 69929.798 & 69411.897 & $-647.479(0.6016)$ & 0.788 \\
\hline
\end{tabular}

Notes: LogL Log likelihood value; AIC Akaike information criterion; BIC Bayesian information criterion; SABIC Sample-size adjusted Bayesian information criterion; $L M R$-LRT Adjusted Lo-Mendell-Rubin likelihood ratio test. A statistical significant LMR LRT (i.e., p<.05) indicates that the $k$ profile model fits the data statistically better than does the $k-1$ profile model. 
Table 5

Within Profile Z-Score Means and Significant Differences Between Profiles by Variable

\begin{tabular}{|c|c|c|c|c|c|}
\hline Variable & $\begin{array}{l}\text { Profile } 1 \mathrm{M} \\
\text { (SE) }\end{array}$ & $\begin{array}{l}\text { Profile } 2 \mathrm{M} \\
\text { (SE) }\end{array}$ & $\begin{array}{l}\text { Profile } 3 \mathrm{M} \\
\quad \text { (SE) }\end{array}$ & $\begin{array}{l}\text { Profile } 4 \mathrm{M} \\
\text { (SE) }\end{array}$ & Significant differences \\
\hline $\begin{array}{l}\text { 1. } \mathrm{T}-\text { Academic } \\
\text { performance }\end{array}$ & $-0.20(.18)$ & $-0.36(.09)$ & $-0.20(.15)$ & $0.28(.08)$ & $1<4 * * *, 2<4 * * *, 3<4 * * *$ \\
\hline $\begin{array}{l}\text { 2. S - Woodcock } \\
\text { Johnson }\end{array}$ & $-0.03(.11)$ & $-0.07(.07)$ & $-0.17(.13)$ & $0.20(.08)$ & $1<4 * * *, 2<4 * * *, 3<4 * * *$ \\
\hline 3. $\mathrm{T}$ - Days absent & $0.09(.13)$ & $-0.03(.10)$ & $0.08(.12)$ & $0.11(.07)$ & $2>4 * * *$ \\
\hline $\begin{array}{l}\text { 4. S - Gets along w/ } \\
\text { other students }\end{array}$ & $-0.28(.13)$ & $-0.13(.07)$ & $-0.46(.12)$ & $0.33(.06)$ & $1<2 * * *, 1<4 * * *, 2>3 * *, 2<4 * * *, 3<4 * * *$ \\
\hline $\begin{array}{l}\text { 5. } \mathrm{S}-\text { Gets along w/ } \\
\text { teachers }\end{array}$ & $-0.50(.16)$ & $-0.20(.10)$ & $-0.81(.15)$ & $0.44(.05)$ & $1<2 * * *, 1<4 * * *, 2>3 * * *, 2<4 * * *, 3<4 * * *$ \\
\hline 6. $S$ - Enjoy school & $-0.88(.15)$ & $-0.24(.08)$ & $-0.51(.15)$ & $0.48(.08)$ & $1<2 * * *, 1<3 * * *, 1<4 * * *, 2<4 * * *, 3<4 * * *$ \\
\hline 7. $S$ - Hate school & $-0.55(.19)$ & $-0.27(.09)$ & $-0.44(.17)$ & $0.47(.05)$ & $1>2^{* * *}, 1>3 * *, \underset{3>4 * * *}{1>4 * *}, 2<3 *, 2>4 * * *$ \\
\hline $\begin{array}{l}\text { 8. } \mathrm{S} \text { - Find classes } \\
\text { interesting }\end{array}$ & $-0.64(.11)$ & $-0.06(.09)$ & $-0.48(.13)$ & $0.40(.09)$ & 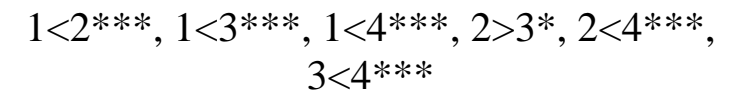 \\
\hline $\begin{array}{l}\text { 9. } S \text { - Try your best on } \\
\text { work }\end{array}$ & $-0.46(.16)$ & $-0.13(.08)$ & $-0.28(.15)$ & $0.35(.06)$ & $1<2 * * *, 1<4 * * *, 2>3 * * *, 2<4 * * *, 3<4 * * *$ \\
\hline 10. S - Pay attention & $-0.47(.15)$ & $-0.31(.08)$ & $-0.75(.19)$ & $0.41(.08)$ & $\begin{array}{c}1<2 * *, 1>3 *, 1<4 * * *, 2>3 * * *, 2<4 * * *, \\
3<4 * * *\end{array}$ \\
\hline $\begin{array}{l}\text { 11. } \mathrm{S} \text { - Complete } \\
\text { homework }\end{array}$ & $-0.35(.15)$ & $-0.21(.09)$ & $-0.58(.14)$ & $0.42(.05)$ & $1<2 * * *, 1<4 * * *, 2>3 * * *, 2<4 * * *, 3<4 * * *$ \\
\hline $\begin{array}{l}\text { 12. } \mathrm{T}-\mathrm{SSRS} \\
\text { classroom behavior }\end{array}$ & $-0.00(.17)$ & $-0.50(.09)$ & $-0.32(.19)$ & $0.36(.08)$ & $1>2 *, 1<4 * * *, 2<4 * * *, 3<4 * * *$ \\
\hline $\begin{array}{l}\text { 13. } \mathrm{T} \text { - Contact parents } \\
\text { re behavior }\end{array}$ & $0.01(.18)$ & $-0.65(.09)$ & $-0.53(.18)$ & $0.31(.09)$ & $1>2 * * *, 1>3 * * *, 1<4 * * *, 2<4 * * *, 3<4 * * *$ \\
\hline 14. $\mathrm{S}-$ Sent to office & $0.60(.00)$ & $-0.68(.00)$ & $-2.45(.08)$ & $0.60(.00)$ & $1<2 * * *, 1<3 * * *, 2<3 * * *, 2>4 * * *, 3>4 * * *$ \\
\hline
\end{tabular}

Notes: $*<.05, * *<.01, * * *<.001 . \mathrm{S}$ indicates student rated and completed variables. T indicates teacher rated variables. 
Table 6

Within Profile Means and Percentages for Demographic, Child Welfare, and Mental Health Variables

\begin{tabular}{|c|c|c|c|c|c|}
\hline Variable & $\begin{array}{l}\text { Overall M } \\
(\mathrm{SD})\end{array}$ & $\begin{array}{l}\text { Profile } 1 \mathrm{M} \\
(\mathrm{SD})\end{array}$ & $\begin{array}{l}\text { Profile } 2 \mathrm{M} \\
(\mathrm{SD})\end{array}$ & $\begin{array}{c}\text { Profile } 3 \mathrm{M} \\
(\mathrm{SD})\end{array}$ & $\begin{array}{l}\text { Profile } 4 \mathrm{M} \\
(\mathrm{SD})\end{array}$ \\
\hline Age & $9.96(2.88)$ & $10.27(2.89)$ & $10.36(2.92)$ & $10.73(2.89)$ & $9.52(2.80)$ \\
\hline Maltreatment Severity & $2.38(1.02)$ & $2.47(1.00)$ & $2.31(0.99)$ & $2.32(1.02)$ & $2.40(1.03)$ \\
\hline Wave 1 Mental Health T-Score & $59.36(12.42)$ & $60.40(12.19)$ & $61.57(12.03)$ & $64.12(11.64)$ & $57.12(12.35)$ \\
\hline \multirow[t]{2}{*}{ Wave 4 Mental Health T-Score } & $57.32(12.63)$ & $57.91(12.01)$ & $59.39(11.89)$ & $62.11(12.18)$ & $55.36(12.93)$ \\
\hline & Overall \% & Profile $1 \%$ & Profile $2 \%$ & Profile $3 \%$ & Profile $4 \%$ \\
\hline \multicolumn{6}{|l|}{ Gender } \\
\hline Female & 52.8 & 54.6 & 39.5 & 39.0 & 60.8 \\
\hline Male & 47.2 & 45.4 & 60.5 & 61.0 & 39.2 \\
\hline \multicolumn{6}{|l|}{ Race } \\
\hline White & 45.7 & 43.2 & 44.4 & 43.1 & 47.5 \\
\hline Black & 29.6 & 32.1 & 33.9 & 32.1 & 26.4 \\
\hline Hispanic & 16.5 & 16.7 & 14.9 & 15.4 & 17.3 \\
\hline Other & 7.9 & 7.6 & 6.4 & 9.3 & 8.5 \\
\hline \multicolumn{6}{|l|}{ Alleged Type of Abuse } \\
\hline Physical & 23.6 & 21.1 & 25.9 & 28.5 & 22.5 \\
\hline Sexual & 16.5 & 14.1 & 14.6 & 15.9 & 18.2 \\
\hline Emotional & 7.0 & 4.9 & 6.4 & 8.1 & 7.9 \\
\hline Neglect & 38.3 & 40.3 & 39.2 & 36.2 & 37.6 \\
\hline Other & 6.3 & 8.2 & 5.4 & 5.3 & 6.1 \\
\hline \multicolumn{6}{|l|}{ Substantiation of Maltreatment } \\
\hline Substantiated & 60.2 & 62.9 & 57.9 & 64.2 & 59.6 \\
\hline Other Than Substantiated & 39.8 & 37.1 & 42.1 & 35.8 & 40.4 \\
\hline
\end{tabular}


Table 7

Likelihood Ratio Tests of Multinomial Logistic Regression

\begin{tabular}{lcccc}
\hline Effect & $\begin{array}{l}\text {-2 Log Likelihood } \\
\text { of Reduced Model }\end{array}$ & \multicolumn{3}{c}{ Likelihood Ratio Tests } \\
\cline { 3 - 5 } & & & & \\
\cline { 3 - 5 } & & Chi-Square & df & $\mathrm{p}$ \\
\hline Intercept & 4261.854 & .000 & 0 & - \\
Age & 4329.695 & 67.841 & 3 & $<.001$ \\
Gender & 4359.395 & 97.541 & 3 & $<.001$ \\
Race & 4278.087 & 16.232 & 12 & .181 \\
Maltreatment type & 4279.051 & 17.197 & 12 & .142 \\
Substantiation of maltreatment & 4266.138 & 4.284 & 3 & .232 \\
Maltreatment severity & 4269.743 & 7.889 & 3 & .048 \\
\hline
\end{tabular}


Table 8

Parameter Estimates of the Multinomial Logistic Regression

\begin{tabular}{|c|c|c|c|c|c|c|c|c|c|}
\hline & & \multirow[b]{3}{*}{ B } & \multirow{2}{*}{\multicolumn{2}{|c|}{ Standard }} & \multirow[b]{3}{*}{ df } & \multirow[b]{3}{*}{$\mathrm{p}$} & \multirow[b]{3}{*}{$\operatorname{Exp}(B)$} & \multicolumn{2}{|c|}{$\begin{array}{l}\text { 95\% Confidence } \\
\text { Interval for } \operatorname{Exp}(\mathrm{B})\end{array}$} \\
\hline & & & & & & & & Lower & Upper \\
\hline & & & Error & Wald & & & & Bound & Bound \\
\hline \multirow[t]{16}{*}{ Profile 1} & Intercept & -1.838 & .395 & 21.665 & 1 & .000 & & & \\
\hline & Age & .094 & .020 & 21.283 & 1 & .000 & 1.099 & 1.056 & 1.144 \\
\hline & Maltreatment severity & .092 & .066 & 1.938 & 1 & .164 & 1.096 & .963 & 1.247 \\
\hline & Race - Black & .276 & .230 & 1.437 & 1 & .231 & 1.318 & .839 & 2.070 \\
\hline & Race - White & .106 & .220 & .234 & 1 & .628 & 1.112 & .723 & 1.711 \\
\hline & Race -Hispanic & .191 & .246 & .599 & 1 & .439 & 1.210 & .746 & 1.962 \\
\hline & Race - Other & $0^{\mathrm{b}}$ & - & - & 0 & - & - & - & - \\
\hline & Maltreatment substantiated & -.050 & .136 & .136 & 1 & .712 & .951 & .729 & 1.241 \\
\hline & Other than substantiated & $0^{\mathrm{b}}$ & - & - & 0 & - & - & - & - \\
\hline & Abuse - Physical & -.372 & .229 & 2.633 & 1 & .105 & .690 & .440 & 1.080 \\
\hline & Abuse - Sexual & -.545 & .245 & 4.965 & 1 & .026 & .580 & .359 & .936 \\
\hline & Abuse - Emotional & -.777 & .304 & 6.513 & 1 & .011 & .460 & .253 & .835 \\
\hline & Abuse-Neglect & -.209 & .215 & .946 & 1 & .331 & .811 & .533 & 1.236 \\
\hline & Abuse - Other & $0^{\mathrm{b}}$ & - & - & 0 & - & - & - & - \\
\hline & Gender - Female & -.365 & .118 & 9.503 & 1 & .002 & .694 & .551 & .876 \\
\hline & Gender - Male & $0^{\mathrm{b}}$ & - & - & 0 & - & - & - & - \\
\hline \multirow[t]{6}{*}{ Profile 2} & Intercept & -1.782 & .380 & 21.966 & 1 & .000 & - & - & - \\
\hline & Age & .117 & .019 & 38.585 & 1 & .000 & 1.124 & 1.083 & 1.166 \\
\hline & Maltreatment severity & -.069 & .061 & 1.277 & 1 & .258 & .933 & .828 & 1.052 \\
\hline & Race - Black & .510 & .217 & 5.534 & 1 & .019 & 1.666 & 1.089 & 2.549 \\
\hline & Race - White & .228 & .209 & 1.193 & 1 & .275 & 1.256 & .834 & 1.891 \\
\hline & Race -Hispanic & .142 & .236 & .362 & 1 & .548 & 1.153 & .726 & 1.831 \\
\hline
\end{tabular}




\begin{tabular}{|c|c|c|c|c|c|c|c|c|c|}
\hline & Race - Other & $0^{\mathrm{b}}$ & - & - & 0 & - & - & - & - \\
\hline & Maltreatment substantiated & -.050 & .124 & .162 & 1 & .688 & .951 & .746 & 1.214 \\
\hline & Other than substantiated & $0^{\mathrm{b}}$ & - & - & 0 & - & - & - & - \\
\hline & Abuse - Physical & .276 & .235 & 1.382 & 1 & .240 & 1.318 & .832 & 2.088 \\
\hline & Abuse - Sexual & .134 & .250 & .289 & 1 & .591 & 1.144 & .701 & 1.865 \\
\hline & Abuse - Emotional & .020 & .286 & .005 & 1 & .945 & 1.020 & .582 & 1.788 \\
\hline & Abuse -Neglect & .210 & .226 & .864 & 1 & .353 & 1.234 & .792 & 1.923 \\
\hline & Abuse - Other & $0^{\mathrm{b}}$ & - & - & 0 & - & - & - & - \\
\hline & Gender - Female & -.904 & .109 & 68.641 & 1 & .000 & .405 & .327 & .502 \\
\hline & Gender - Male & $0^{\mathrm{b}}$ & - & - & 0 & - & - & - & - \\
\hline \multirow[t]{16}{*}{ Profile 3} & Intercept & -2.428 & .521 & 21.678 & 1 & .000 & - & - & - \\
\hline & Age & .162 & .026 & 37.447 & 1 & .000 & 1.176 & 1.116 & 1.238 \\
\hline & Maltreatment severity & -.153 & .086 & 3.134 & 1 & .077 & .858 & .725 & 1.016 \\
\hline & Race - Black & .061 & .270 & .051 & 1 & .822 & 1.063 & .626 & 1.806 \\
\hline & Race - White & -.256 & .260 & .976 & 1 & .323 & .774 & .465 & 1.287 \\
\hline & Race -Hispanic & -.209 & .300 & .489 & 1 & .485 & .811 & .451 & 1.459 \\
\hline & Race - Other & $0^{\mathrm{b}}$ & - & - & 0 & - & - & - & - \\
\hline & Maltreatment substantiated & -.363 & .177 & 4.211 & 1 & .040 & .696 & .492 & .984 \\
\hline & Other than substantiated & $0^{\mathrm{b}}$ & - & - & 0 & - & - & - & - \\
\hline & Abuse - Physical & .393 & .335 & 1.377 & 1 & .241 & 1.481 & .768 & 2.856 \\
\hline & Abuse - Sexual & .313 & .356 & .775 & 1 & .379 & 1.368 & .681 & 2.749 \\
\hline & Abuse - Emotional & .309 & .395 & .610 & 1 & .435 & 1.361 & .628 & 2.952 \\
\hline & Abuse-Neglect & .214 & .326 & .429 & 1 & .512 & 1.238 & .653 & 2.347 \\
\hline & Abuse - Other & $0^{\mathrm{b}}$ & - & - & 0 & - & - & - & - \\
\hline & Gender - Female & -1.067 & .155 & 47.319 & 1 & .000 & .344 & .254 & .466 \\
\hline & Gender - Male & $0^{\mathrm{b}}$ & - & - & 0 & - & - & - & - \\
\hline
\end{tabular}

Notes: Profile 4 is the reference category. $\mathrm{b}$. This parameter is set to zero because it is redundant. 
Table 9

Analyses of Variance of Mental Health Symptomology at Wave 4 by Profile

\begin{tabular}{lcccc}
\hline Profile & Vs. Profile & Mean Difference & Standard Error & $p$ \\
\hline 1 & 2 & -1.478 & .839 & .293 \\
& 3 & $-4.199^{* *}$ & 1.087 & .001 \\
& 4 & $2.552^{* *}$ & .726 & .003 \\
\hline 2 & 1 & 1.478 & .839 & .293 \\
& 3 & $-2.721^{*}$ & 1.054 & .049 \\
& 4 & $4.030^{* * *}$ & .676 & .000 \\
\hline 3 & 1 & $4.199^{* *}$ & 1.087 & .001 \\
& 2 & $2.721^{*}$ & 1.054 & .049 \\
& 4 & $6.751^{* * *}$ & .966 & .000 \\
\hline 4 & 1 & $-2.552^{* *}$ & .726 & .003 \\
& 2 & $-4.030^{* * *}$ & .676 & .000 \\
& 3 & $-6.751^{* * *}$ & .966 & .000 \\
\hline
\end{tabular}

Note: $* p<.05, * * p<.01, * * * p<.001 . N=2,202$. 
Table 10

Hierarchal Regressions Predicting Mental Health Outcomes

\begin{tabular}{|c|c|c|c|}
\hline & $\mathrm{B}(\mathrm{SE})$ & $\beta$ & $t$ \\
\hline W1 Mental Health & $0.55(0.20)$ & 0.53 & $27.62 * * *$ \\
\hline \multicolumn{4}{|c|}{ Race/Ethnicity (Reference is White $(n=949))$} \\
\hline Black $(n=591)$ & $-.49(.56)$ & -.02 & -.87 \\
\hline Hispanic $(n=327)$ & $-1.04(.69)$ & -.03 & -1.52 \\
\hline Other $(n=137)$ & $-.23(.97)$ & -.01 & -.23 \\
\hline \multicolumn{4}{|c|}{ Abuse Type (Reference is Neglect $(n=839))$} \\
\hline Physical $(n=512)$ & $-.12(.59)$ & -.004 & -.20 \\
\hline Sexual $(n=355)$ & $-.56(.68)$ & -.02 & -.82 \\
\hline Emotional $(n=151)$ & $-1.19(.94)$ & -.03 & -1.27 \\
\hline Other $(n=131)$ & $.38(.99)$ & .01 & .38 \\
\hline Substantiation of maltreatment & $-.02(.56)$ & -.001 & -.03 \\
\hline Severity of maltreatment & $.68(.28)$ & .05 & $2.38 *$ \\
\hline \multicolumn{4}{|c|}{ Profile Membership (Reference is Profile $4(n=1025)$} \\
\hline Profile $1(n=352)$ & $1.14(.66)$ & .03 & $1.72 \dagger$ \\
\hline Profile $2(n=443)$ & $1.79(.61)$ & .06 & $2.93 * *$ \\
\hline Profile $3(n=185)$ & $2.84(.86)$ & .07 & $3.31 * *$ \\
\hline \multicolumn{4}{|l|}{$3^{\text {rd }}$ Step } \\
\hline Profile $1 \mathrm{X}$ Severity of maltreatment & $.43(.65)$ & .03 & .51 \\
\hline Profile $2 \mathrm{X}$ Severity of maltreatment & $.67(.60)$ & .06 & 1.12 \\
\hline Profile $3 \mathrm{X}$ Severity of maltreatment & $.73(.83)$ & .04 & .88 \\
\hline
\end{tabular}

Notes: $\dagger p<.10, * p<.05, * * p<.01, * * * p<.001 . N=1,987$. All values come from step 2 of the model, except values for the interaction terms come, which from step 3 of the model. Model step 1 summary statistics: $R^{2}=.300, F(10,2378)=101.81, p<.001$. Model step 2 summary statistics: $R^{2}=.314, F(13,1973)=69.337, p<.001, \Delta R^{2}=.014$, $F$ change $=13.42, p<.001$. Model step 3 summary statistics: $R^{2}=.314, F(16,1970)=$ 56.413, $p<.001, \Delta R^{2}<.001, F$ change $<.001, p=1.00$. 
APPENDIX B: FIGURES 
Figure 1

Within School Adaptation Profile Mean Z-scores for Indicators of School Adaptation

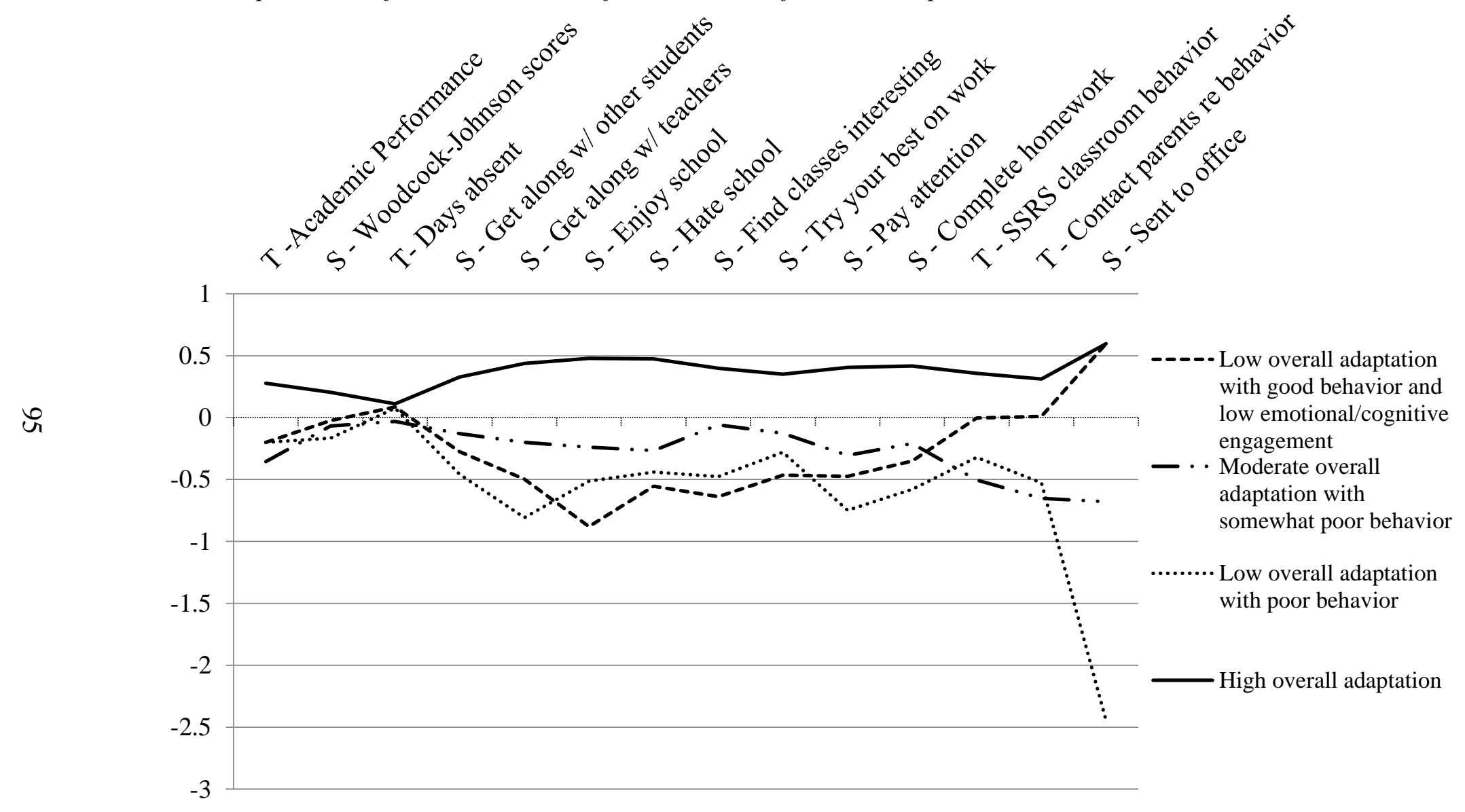

